IZA DP No. 8465

Unconditional and Conditional Wage Polarization in Europe

Paolo Naticchioni

Giuseppe Ragusa

Riccardo Massari

September 2014 


\title{
Unconditional and Conditional Wage Polarization in Europe
}

\author{
Paolo Naticchioni \\ University of Roma Tre \\ and IZA
}

Giuseppe Ragusa

Luiss University

Riccardo Massari

Sapienza University of Rome

\section{Discussion Paper No. 8465 \\ September 2014}

\author{
IZA \\ P.O. Box 7240 \\ 53072 Bonn \\ Germany \\ Phone: +49-228-3894-0 \\ Fax: +49-228-3894-180 \\ E-mail: iza@iza.org
}

\begin{abstract}
Any opinions expressed here are those of the author(s) and not those of IZA. Research published in this series may include views on policy, but the institute itself takes no institutional policy positions. The IZA research network is committed to the IZA Guiding Principles of Research Integrity.

The Institute for the Study of Labor (IZA) in Bonn is a local and virtual international research center and a place of communication between science, politics and business. IZA is an independent nonprofit organization supported by Deutsche Post Foundation. The center is associated with the University of Bonn and offers a stimulating research environment through its international network, workshops and conferences, data service, project support, research visits and doctoral program. IZA engages in (i) original and internationally competitive research in all fields of labor economics, (ii) development of policy concepts, and (iii) dissemination of research results and concepts to the interested public.
\end{abstract}

IZA Discussion Papers often represent preliminary work and are circulated to encourage discussion. Citation of such a paper should account for its provisional character. A revised version may be available directly from the author. 


\section{ABSTRACT}

\section{Unconditional and Conditional Wage Polarization in Europe*}

This paper investigates the dynamics of the distribution of unconditional and conditional - on technology - wages in Europe, using both industry and individual level data for the period 1995-2007. We find that the unconditional wage distribution shows scant signs of polarization in Europe. On the other hand, the effect of technology is more nuanced. At the industry level, technological changes have an effect on polarization of jobs, but not on polarization of wages. At the individual level, we use a counterfactual distributional analysis which accounts for the heterogeneity of tasks across occupations, and we find only mild evidence of wage polarization. Technology affects the lower and upper part of the wage distribution in different ways, with service tasks affecting the lower quantiles and abstract tasks affecting the higher ones.

JEL Classification: J3, J5

Keywords: $\quad$ wage inequality, polarization, occupational tasks, offshoring, RIF-regressions

Corresponding author:

Paolo Naticchioni

Roma Tre University

Faculty of Economics

Via Silvio D'Amico 77

00154 Rome

Italy

E-mail: p.naticchioni@gmail.com

\footnotetext{
* We thank Carlo Dell'Aringa, Wen Hao Chen, Nicole Fortin, Thomas Lemieux, Marco Leonardi, Elisabetta Magnani, Alan Manning, Francesca Mazzolari, Raul Ramos, Giovanni Sulis, for their suggestions, and the participants in seminars held at Cattolica University (MILLS Seminar, Milan), OFCE-Science Po, CeLEG-Luiss (Rome), University of Padova, Barcelona (UB), Cagliari, Naples Partenope, Rome (Univ. La Sapienza), CREI (Univ. Roma Tre) School of Management of Politecnico of Milan, and participants in the conferences ECINEQ (Catania), AIEL (Milan), SIE (Rome), Royal Economic Society (Cambridge). Paolo Naticchioni and Giuseppe Ragusa acknowledge financial support from the European project NEUJOBS.
} 


\section{Introduction}

There is now a large body of literature documenting the growth of the share of employment in high skill occupations and the simultaneous growth of low skill occupations occurring in the US and in Europe (Autor et al., 2006; Goos et al., 2009). Many hypotheses have been put forward to explain job polarization. The routinization hypothesis (Autor et al., 2003; Goos and Manning, 2007) suggests that polarization in occupation occurs because technical change tends to replace routine jobs - generally performed by medium skilled workers. Other explanations, not alternative but rather complementary to the routinization hypothesis, view job polarization as the effect of globalization (Blinder, 2009) or as being the result of high skilled consumption spillovers (Mazzolari and Ragusa, 2013). A part of the literature has already established a link between the polarization of the European labor market and technology. Goos et al. (2014) investigate the effects of technology, globalization, institutions and product demand on the employment structure and conclude that technology shifts may account for the observed trends in polarization.

In the US labor market job polarization has been accompanied by a pattern of wage growth polarization - that is, the tendency of lower and upper quantiles of the wage distribution to grow faster than those at the middle (Acemoglu and Autor, 2011; Firpo et al., 2013). As a result, upper-tail inequality, measured as the 90-50 wage gap has been steadily increasing, whereas lower-tail inequality, measured as the 50-10 wage gap, has been falling or flat since the end of the 1980s. A similar pattern of mild wage polarization has been found in the UK (Machin, 2011) and in Germany (Antonczyk et al., 2010; Dustmann et al., 2008), but the number of empirical studies on wage polarization in Europe is still limited. Using OECD industry level data Michaels et al. (2013) focus on OECD and European countries, showing that technology has a differential effect on the bill share of workers with different skills, which is suggestive of "polarization" due to technology and thus broadly consistent with the routinization hypothesis.

The goal of this paper is to add to the empirical evidence on wage polarization in Europe. Our focus is twofold. Firstly, we investigate whether European wages have been subject to the same polarizing forces that have affected the US labor market. Secondly, we study the impact of technology on wages to ascertain whether routinization may be playing a role in Europe. With 
the first approach we want to uncover what we call "unconditional" polarization in wages; with the second the "conditional" (on technology) polarization. The two do not need to be related: while wages may not show signs of polarization, technology may affect the wage distribution in a way that is consistent with the routinization hypothesis — or any other technology-based explanation of polarization.

We make use of both industry and individual level data. At the industry level we use the World Input-Output Database (WIOD) merged with the data on Capital, Labour, Energy, Materials and Service (EU KLEMS). More specifically, we use data on industry output, value added, ICT $(K)$ and non-ICT $(C)$ capital compensation, wages and employment by education level. At the individual level, we created a new dataset by harmonizing the European Community Household Panel (ECHP) and the European Union Statistics on Income and Living Conditions (EU-SILC).

Analyzing the period 1995-2007, we find little evidence of polarization of the European unconditional wage distribution: both industry and individual data provide evidence hardly consistent with increasing wage polarization.

As far as the conditional impact of technology is concerned, the evidence, as expected, is more nuanced. At the aggregate level, we investigate "long run" differences for the period 1995-2007, focusing on the impact of ICT intensity on relative wages between high and medium skilled, and between medium and low skilled. We find that changes in ICT intensity are generally correlated with changes in relative bill shares in a direction that is consistent with the routinization hypothesis. However, these changes in wage bill shares are almost entirely accounted for by changes in relative hours worked. The findings are robust to different identification strategies used to deal with unobserved heterogeneity and potential endogeneity of the ICT intensity measure.

We then move to individual level data, since Autor and Dorn (2013) and Firpo et al. (2013), among others, have pointed out that technological progress acts within industry, through the effects of the interaction of tasks and skills across occupations. While industry level analysis captures the between-industry impact of technology, it misses its between-occupation effect. Other shortcomings of the industry level analysis are the coarseness of the measure of skill and 
the inability to control for heterogeneity of workers.

The individual level analysis uses occupational task measures derived from Goos et al. (2009) to proxy for technological characteristics of various occupations, such as measures of the level of routinization (abstract, routine, service tasks) and of the extent to which jobs are offshorable (Goos et al., 2014). The analysis is conducted by means of the counterfactual decomposition methodology proposed by Fortin et al. (2010). This technique enables the identification of composition and wage structure effects along the whole wage distribution. While the results depend to some extent on which measure of wage we use (hourly wages vs. yearly earnings), we can draw the following conclusions. First, we find that technology has only a weak polarizing effect on the wage distribution. The effect is mainly due to the wage structure effect and, in particular, to service tasks at the lower tail of the wage distribution (Autor and Dorn, 2013; Mazzolari and Ragusa, 2013) and to abstract tasks at the upper tail of the distribution (Firpo et al., 2013). The impact of offshoring, on the other hand, is constant along the wage distribution, which is consistent with Goos et al. (2014). Neither the other components of the wage structure effect (demographic, institutions, education) nor the composition effects exert a polarizing effect on the wages distribution. A finding we consider particularly interesting is that education plays not role in the increase in wage/earnings inequality and is not linked to polarization. This is at odds with what the literature has established in the case of the US (Acemoglu and Autor, 2011). It is however consistent with the analysis in OECD (2011). We also point out that institutional features of the labour market, e.g. the increase in the shares of temporary and part-time contracts, have played a role in increasing wage inequality, especially at the lower end of the earnings distribution.

Our results can be seen as a further evidence that in Europe the effects of technology on the labor market are different from those at work in the US (Krugman, 1994; Bertola and Ichino, 1995). Such differences may be accounted for with institutions and preferences for limited wage dispersion. In such an environment, changes in the labour market take place mainly through composition effects in the labour force, i.e., changes in occupation composition rather than wages. 


\section{Industry level evidence}

In this section we present aggregate evidence on the polarization of the European labor market with particular emphasis on the impact of information and communications technology (ICT) on labour market outcome, using industry level data. Differently from Michaels et al. (2013), which used the Growth and Productivity Accounts data (EU KLEMS), our analysis is based on data obtained merging two different datasets: the World Input-Output Database (WIOD) and the EU KLEMS. ${ }^{1}$ These databases have largely been constructed by harmonizing data obtained from national statistical institutes. Details about this harmonization process and the methodology used to construct industry-wide input-output measures are exhaustively given in O'Mahony and Timmer (2009) and Timmer (2012).

We use WIOD data on wages and employment by skill types. Industry-wide data by skill is available for three groups: high-(H), medium-(M), and low-skilled (L). Workers are assigned to these skill levels according to their education attainment (tertiary, upper secondary and lower than upper secondary, respectively).

It is also worth stressing that WIOD data for education are much more reliable than the EU KLEMS data used in Michaels et al. (2013). As shown in Table B in annex B, in EU KLEMS for some countries figures are clearly implausible. For Italy and Netherland the share of workers with medium education is around $85 \%$, while the share of low skilled is lower than $10 \%$. Also for France and for the UK the shares of medium skilled are rather high. The figures emerging from WIOD are much closer to the education levels available at the country level from EUROSTAT (Table B).

Using WIOD data, for each skill group we have data on wage bill share $\left(B S^{H}, B S^{M}, B S^{L}\right)$, hours worked $\left(N^{H}, N^{M}, N^{L}\right)$, and wages $\left(W^{H}, W^{M}, W^{L}\right)$. While WIOD has data on capital services, it does not breakup capital input measures into assets types. We use the ICT $(K)$ and non-ICT $(C)$ capital input measures from EU KLEMS. In particular, we construct a measure of industry intensity in new technologies using ICT capital compensation which we divide by

\footnotetext{
${ }^{1}$ There are at the time of writing four different releases of the EU KLEMS database: March 2007, March 2008, November 2009, and March 2011. We use the March 2011.
} 
value added $(Q) .^{2}$

Our final dataset has information about twelve European countries: Austria, Belgium, Denmark, Finland, France, Germany, Ireland, Italy, Netherlands, Spain, Sweden, and the United Kingdom. For the three remaining EU15 countries (Greece, Luxembourg, and Portugal) we do not have information about either industry specific wages by education level or capital compensation. For each country data covers all NACE classification (ver. 1.1) two digits industries. We do not consider agriculture and fishing. The full description of the industries considered in the analysis is given in Table 1, which also shows how industries are partitioned into two groups: manufacturing and service. The time span of the analysis is the period 1995-2007. ${ }^{3}$

The upper panel of Table 2 shows the mean values for the 1995-2007 log change of relative (both high to medium skilled and medium to low skilled) wage bill share, relative hours worked and wages, as well as the log changes over the same period of ICT and non-ICT capital over value added. Ireland is the country with the highest increase in the wage bill accruing to the high skilled relative to medium skilled. Countries with similar rate of growth are the Netherlands, Austria, and Denmark. In Belgium, Spain and Italy the wage bill share of the high relative to the medium skilled has instead decreased in the period considered. The wage bill share of medium skilled relative to that of low skilled has instead increased in all countries with the exception of Germany and Denmark. As for hours worked, they have increased more for the high skilled than for the medium skilled in all countries with the exception of Spain. Denmark and Germany show a modest decline of hours worked by the medium skilled relative to the low skilled. As for wages, relative high-medium skilled wages have declined for the majority of countries with Germany, Ireland, and Finland being notable exceptions. For the ratio between wages of medium and low skilled the evidence is more mixed. Finally, as far as ICT capital intensity is concerned, all countries show an increase, with the exception of Ireland. France and Italy are the countries with the smallest change in ICT intensity over the period considered.

\footnotetext{
${ }^{2}$ Capital compensation is not to be confused with capital stock. Capital stock is the value of the aggregate of all machinery, infrastructure, buildings and intangibles capital available in a given industry. Capital compensation is the cost of capital that is actively used in production. See also Michaels et al. (2013).

${ }^{3}$ We could potentially extend the time interval considered up to 2009 , but we prefer to consider the shorter period, since considering 2008 and 2009 is likely to affect the results due to the international financial crises.
} 
The lower panel of Table 2 shows instead the initial levels of the same variables in 1995.

\subsection{Industry data: unconditional wage polarization}

We start by investigating the dynamic of Europe-wide hourly wages. In Figure 1 we plot trends in real absolute and relative wages once data is aggregate for the twelve countries across all industries. This aggregation is done in two steps. First, we construct country-wide measure of skill-specific hours worked and total wage compensation, aggregated by industry. These wage bills are converted in Euro using historical exchange rates and are deflated using the country specific Consumer Price Index (CPI). Hours and compensations are then summed up over skills and countries. The aggregated wages, which are plotted in Figure 1, are thus obtained by dividing the aggregate wage bill by the aggregate number of hours worked. The right panel show that the growth of real wages has declined since 2002 for all skill groups. Real wages of the high-skilled group relative to medium skilled group were growing at the beginning of the period, but started to decline in 2000 (left panel). The ratio between medium and low skilled wages were instead increasing up to 2000, and started to decline soon after. Changes are however extremely contained: the high skilled relative to medium skilled went from 1.56 in 1995 to 1.53 in 2007 (a $1.5 \%$ percent decline over a 12 years period) and the medium skilled relative to low skilled wages went from 1.33 to 1.32 (a meager $0.9 \%$ decline). At first sight, this aggregate descriptive evidence does not provide any support to trends in wage polarization in Europe.

As shown in Figure 2, the wage dynamic by skill is characterized by country heterogeneity. High skill wages have increased steadily for Denmark, Finland, Ireland, Netherland, Sweden, and UK. Other countries show either stagnating wages - Belgium, France, and Germany —or a declining trend-Austria and Italy. As far as wages of medium and low skilled are concerned, the picture is even more mixed. Only three countries, namely Finland, Ireland, and Germany, show a reduction of medium skilled wages and a contemporaneous increase in low skilled wages. This evidence is suggestive of a European wage dynamics that show little signs of "unconditional" polarization. 


\subsection{Industry data: conditional wage polarization}

The next question is whether technological change is exerting a "polarizing" force on the European labor market. As shown in Figure 3, which plots the average changes in ICT intensity over the period 1995-2007 aggregated across countries, there is an high degree of variation of ICT intensity across sectors. Furthermore, industries with the highest increase in ICT intensity are generally service industries. In particular, financial intermediation $(\mathrm{J})$ is by far the industry with the highest increase in ICT intensity, followed by the Post and Telecommunications industry (64).

Figures 4 plots 1995-2007 changes in ICT against log changes in the three skill groups relative wage bill share. When considering the whole set of industries (right panel), the wage bill share of high skilled relative to medium skilled has on average increased more in industries that have experienced higher changes in ICT. The contrary is true for the wage bill share of the medium skilled relative to the low skilled. It is interesting to note that these correlations change when the sample of industries is divided into service and manufacturing, with the impact being more evident in the service sector for what concerns the ratio high-medium skilled. ${ }^{4}$

To further shed light on how the behavior of ICT investment has impacted the labor market outcomes of different skill groups we turn to a regression analysis. In particular, as in Michaels et al. (2013), we start from the following variable cost function

$$
C V\left(W^{H}, W^{M}, W^{L}, C, K, Q\right)
$$

where $W$ indicates hourly wages with the superscripts $(H, M, L)$ denoting education skill groups: highly educated, medium educated, and low educated workers. By assuming that capital and factor prices are fixed, cost minimization with a translog cost function implies that the wage bill share can be written as

$$
\lambda^{s}=\beta_{H, s} \ln \left(W^{s} / W^{L}\right)+\beta_{M, s} \ln \left(W^{M} / W^{L}\right)+\beta_{C H} \ln (C / Q)+\beta_{K H} \ln (K / Q)+\beta_{Q} \ln (Q),
$$

\footnotetext{
${ }^{4}$ Although we do not report this evidence here, the correlations between wage bill shares of the three education groups and $K / Q$ is rather homogenous across countries, suggesting a similar impact on technology on the labour market structure for the whole set of European countries.
} 
where $\lambda^{s}$ is the wage bill share of skill group $s=\{H, M, L\}$

$$
\lambda^{s}=\frac{W^{s} H^{s}}{W^{H} H^{H}+W^{M} H^{M}+W^{L} H^{L}} .
$$

Our model is based on the three equations defined in (1). We consider the following econometric specification

$$
\ln \lambda_{i c t}^{s}=\alpha_{i c}+\alpha_{i t}+\alpha_{c t}+\alpha_{t}+\alpha_{i}+\alpha_{c}+\beta_{C H}^{s}(C / Q)_{i c t}+\beta_{K H}^{s}(K / Q)_{i c t}+\beta_{Q}^{s} \ln (Q)_{i c t}+\varepsilon_{i c t},
$$

where $i$ denotes the industry, $c$ the country, and $t$ the time period. In this specification we allow for unobserved heterogeneity between industry by country pairs $\left(\alpha_{i c}\right)$, industry by time pairs $\left(\alpha_{i t}\right)$, and country by time pairs $\left(\alpha_{c t}\right)$, as well as industry $\left(\alpha_{i}\right)$, country $\left(\alpha_{c}\right)$, and time fixed effect $\left(\alpha_{t}\right)$. We estimate long time difference (thirteen years) between the relative wage bill share

$$
\begin{aligned}
& \Delta \ln \left(\lambda^{H} / \lambda^{M}\right)_{i c}=\beta_{0}^{H M}+\beta_{1}^{H M} \Delta \ln (C / Q)_{i c}+\beta_{2}^{H M} \Delta \ln (K / Q)_{i c}+\beta_{Q}^{H S} \Delta \ln (Q)_{i c}+\Delta \varepsilon_{i c}^{H M}, \\
& \Delta \ln \left(\lambda^{M} / \lambda^{L}\right)_{i c}=\beta_{0}^{M L}+\beta_{1}^{M L} \Delta \ln (C / Q)_{i c}+\beta_{2}^{M L} \Delta \ln (K / Q)_{i c}+\beta_{Q}^{M L} \Delta \ln (Q)_{i c}+\Delta \varepsilon_{i c}^{M L},
\end{aligned}
$$

where $\Delta$ denotes time difference variables. ${ }^{5}$ Notice that country and industry fixed effects and unobserved heterogeneity between industry and country pairs all drop out because they are time invariant, while the time fixed effect is absorbed in the constant. We also add as control the 1995 initial level of capital over value added and the initial level of value added to take into account industry by country heterogeneity. Further, the unobserved heterogeneity between industry and time and between country and time pairs drop out if they are assumed to be constant by skill level. Since this is a strong assumption, as a robustness check we estimate (2) by including country fixed effects — which amount to assuming that country by time heterogeneity differs between skill group. We weight all regressions by industry-country relative employment. ${ }^{6}$

Specification (2) allows to study the impact of ICT capital on relative wage bill share, but

\footnotetext{
${ }^{5}$ In the estimating equations (2), capital over value added are included in logarithms. As in Michaels et al. (2013), we do so because some industries experiences large increases in these variables. However, the results of this section are robust to the inclusion of the variables in level.

${ }^{6}$ The weights are obtained by dividing the number of employees of each industry-country cell in 1995 by the total employment in the whole sample in 1995.
} 
also to decompose it into hours and wages. Since

$$
\begin{aligned}
& \Delta \ln \left(\lambda^{H} / \lambda^{M}\right)_{i c}=\Delta \ln \left(W^{H} / W^{M}\right)_{i c}+\Delta \ln \left(N^{H} / N^{M}\right)_{i c} \\
& \Delta \ln \left(\lambda^{M} / \lambda^{L}\right)_{i c}=\Delta \ln \left(W^{M} / W^{L}\right)_{i c}+\Delta \ln \left(N^{M} / N^{L}\right)_{i c},
\end{aligned}
$$

we run regression on the log relative difference in wages between two education groups and the log relative difference in hours worked to appraise whether the effect of ICT intensity depends more on changes in relative hours worked or in relative changes in wages.

\subsubsection{Regression results}

Table 3 reports OLS estimations of equation (2) and the decomposition implied by (3)-(4). Column (1) documents that the high skilled relative to the medium skilled wage bill share is positively correlated with changes in ICT intensity, i.e., in $K / Q$. The correlation between medium to low-skilled wage bill share and ICT intensity is instead negative (Column (4)). The coefficients are both statistically and economically significant, suggesting that when considering wage bill shares there is evidence of conditional polarization.

As we decompose wage bill shares into hours and wages, we find that changes in relative wage bill shares tend to be almost totally explained by changes in relative hours worked: about $75 \%$ of the changes in relative wage bill shares, be it high to medium or medium to low, can be explained by changes in relative employment. Further, coefficients associated to relative wages are not even statistically significant. If anything, these correlations suggest that polarization forces act through employment and not through wages. Table 4 reports the results when country fixed effects are added. Since the specification is estimated in differences, these results are robust to the presence of country specific trends correlated with ICT intensity. Controlling for these trends lower the magnitude of the estimated coefficients, but the qualitative picture remains unchanged. Table 5 and Table 6 show the OLS results when the baseline specification is estimated separately for service and manufacturing industries, respectively. The results suggest that the service sector is the one where information technology exerts more polarizing influence. Although the correlations between ICT and wage bill share are positive in the "upper tail" and

negative in the "lower tail" in both sets of industries, the coefficients when only manufacturing 
industries are used are more imprecisely estimated. Yet, as in the case when all industries are used, ICT affects the wage bill share mainly by hours worked and relatively little by changes in wages.

We also take into account endogeneity issues, implementing a two-stage least squares approach where we instrument changes in ICT over value added with the 1995 level of ICT over value added in the United States, as in Michaels et al. (2013). This instrument provides an indicator of the initial ICT intensity of a country, the US, which can be considered the technological leader, and that is not included in our analysis since we focus on European countries. The assumption underlying the validity of the instrument is that industry specific US technological shocks in the 1995 are predetermined, that is, they are not correlated with industry specific shocks to over time changes in ICT intensity of European countries.

The IV results are presented in Table 7 . Since the first stage F statistics is relatively low (8.8), we report the Conditional Likelihood Ratio (CLR) statistic and its relative p-values for testing the null hypothesis that the coefficient on ICT capital is zero. The CLR test has correct size even in presence of weak instruments. The qualitative results are similar to those of Table 3 and do not alter the conclusion on the effect of ICT on relative bill share, hours worked, and wages. In particular, a one standard deviation increase in ICT over value added is associated with a $12 \%$ increase in the high-medium skilled relative bill share and a $5 \%$ decrease in the medium-low skilled relative bill share. Similarly to what we obtained using plain OLS, the largest part of these changes in wage bill share are explained by changes in hours worked, with changes in wages having only a negligible, and not statistically significant, effect. The OLS results are also confirmed when the IV analysis is run for service and manufacturing industries separately. As shown in Table 8 and Table 9, the effect of technology on the service sector is similar, qualitatively and quantitatively, to that we obtained for the whole sample. ${ }^{7}$ When only manufacturing industries are considered, the coefficients on the change of $K / Q$-although showing a similar qualitative pattern - are very imprecisely estimated. In any case, it is difficult to interpret the results contained in these last two tables since the first stage F-statistics is

\footnotetext{
${ }^{7}$ The results reported for these two specifications do not include country fixed effects. When the more robust specification is used, the point estimates are similar, but the precision of the estimated coefficient is smaller.
} 
extremely low in which case inference, even if robust to weak instrument as in the case of the CLR test, is problematic.

Our results suggest that technology is exerting a polarizing impact on the European labor market. The impact is however limited to skill employment composition and does not spill to the wage distribution. We are cautious with our statements for a series of reasons. Using industry level data it is possible to capture only the between sector (or within sector between years) impact of technological change, while recent literature on this topic (Autor and Dorn, 2013; Firpo et al., 2013) has shown that technological progress can affect also the within sector dynamics, mainly with respect to different tasks in different occupations. Furthermore, by only using aggregate data it is not possible to control for individual observed heterogeneity, and also to investigate changes of all percentiles of the wage distribution. For all these reasons, in the next section we turn to individual level data in order to analyze the between occupation impact of technological change.

\section{Micro evidence}

Job and wage polarization have been extensively analyzed at the country level. The evidence of these studies is not conclusive and findings are country specifics. Wage polarization has been detected in Germany (Dustmann et al., 2008), Portugal (Centeno and Novo, 2009), and in the UK (Machin, 2011), even if it has not being explicitly linked to the routinization hypothesis. For France (Charnoz et al., 2011), Spain (Izquierdo and Lacuesta, 2006) and Italy (Naticchioni et al., 2008) the focus of recent studies has been on decreasing inequality and falling returns to education more than on polarization per se.

A challenge in studying the wage dynamics at the European level is that of finding a consistent yet rich data source. We use data from the European Community Household Panel (ECHP) and from the European Income and Living Conditions (EU-SILC). ECHP is a longitudinal survey conducted yearly, from 1994 to 2001, in 15 European Union Member States under the supervision of Eurostat (Statistical Office of the European Communities). EU-SILC is a yearly survey started in 2004 that includes also new EU members and some non EU countries (Norway, Iceland and Cyprus). The two surveys shares many features and can be harmonized to 
provide consistent measures of labor incomes and of relevant demographic characteristics. ${ }^{8}$ In the analysis that follows, we consider the 1996 wave of ECHP and the 2007 wave of EU-SILC. ${ }^{9}$

We consider two measures of labour earnings. The first is the current gross hourly wage deriving from the current main job of the individual. Current wages are only available for a small set of countries, namely: Austria, Greece, Ireland, Italy, Portugal, Spain and the UK. A second alternative measure of labor income can be obtained by considering gross earnings that relate to the year previous to that in which the interview took place. This measure of labour income cover a much wider set of countries (Austria, Belgium, Denmark, Spain, Finland, France, Greece, Ireland, Italy, Luxembourg, Portugal, and the UK). We also do not consider Germany since there is evidence that German EU-SILC data on income is plagued with problems (Hauser, 2008; Frick and Krell, 2010). ${ }^{10}$ Using this measure is potentially problematic because other individual variables refer to the current period. This temporal misalignment might be a source of measurement error for covariates that can change over time, such as indicator for temporary or a part time job, sector, occupation. We believe however that our data is better than that employed by other papers that study European inequality patterns. For instance, data used in OECD (2011) harmonizes data coming from different sources (surveys, administrative registers and tax records) and as such the sample design, the questionnaires, and definitions of the variables vary greatly among countries. ${ }^{11}$

\footnotetext{
${ }^{8}$ These two datasets have not been considered as a unique data source with the exception of Goos et al. (2009, 2014) which combine them to obtain a by occupation measure of wages.

${ }^{9}$ Results remain similar from a qualitative point of view when using different survey years, such as 1995 and/or 2008 (available on request). We decided to use 1996 since it is the year where the variables of the analysis are available for the highest number of countries, and we do not consider years after 2007 in order the have an homogenous period of analysis, without the impact of the economic crisis.

${ }^{10}$ In our data we had the feeling of this problem since the 90-50 ratio decreased over time in Germany, while all the literature stresses that in the same period of time the 90-50 increased. Note that including Germany in the analysis does not alter the results in the lower tail of the distribution, while slight changes occur in the upper tail of the distribution where German data have the main problems.

${ }^{11}$ Atkinson (2008) recognizes that OECD data are well suited for assessing within country changes in the earning distribution, but are less useful for carrying out across countries comparisons.
} 


\subsection{Labor income distribution and unconditional wage polarization}

In Panel A of Table 10 we report the descriptive statistics for the log of gross current hourly wage for the seven countries for which this measure is available. Hourly wages increased on average by $14.6 \%$, but most of the growth is attributable to upper tail growth with the 50th and the 90th percentile increasing by $13.3 \%$ and $26.6 \%$ respectively, as opposed to the 10th percentile which increased only by $2 \%$. As a result, Europe-wide wage inequality, as measured by the 90 th-10th percentile ratio, increased by 24.6 percentage points. There are no signs of wage polarization, since the 90th-50th and 50th-10th percentile ratios increased by $13.3 \%$ and $11.3 \%$ respectively. The same qualitative behavior emerges when the gross hourly wage are adjusted by the Purchasing Power Parity (PPP) deflators, to take into account different costs of living of the national entities. Panel B of Table 10 shows that the 90th-10th percentile ratio increased by $13.5 \%$, with the 90th-50th and 50th-10th ratios increasing by $6.8 \%$ and $6.7 \%$, respectively. Panel $\mathrm{C}$ of Table 10 analyzes log-changes of the previous-year gross earnings. ${ }^{12}$ The 10th percentile of the distribution of this measure of labor income has decreased over time by $3.7 \%$; the 50 th and the 90 th percentile increased by $11.6 \%$ and $13.1 \%$, respectively and the 50th-10th ratio increases by $15.4 \%$ (the 90 th- 10 th ratio increases by only $1.4 \%$ ). Considering the $(\log )$ yearly gross earnings in PPP (Panel D) does not alter the qualitative pattern of changes in inequality.

To sum up, in the period 1996-2007 European income inequality increased considerably. However, wages have not polarized, as shown by the fact that the change in the 50th-10th percentile ratio remains positive for all the different measures of labor income. This evidence is in line with findings of the industry level analysis of the paper.

\subsection{Testing the routinization hypothesis: Conditional wage polarization}

In this section we investigate the relation between technological proxies and wage structure controlling for personal characteristics. The set of covariates are: gender; potential experience

\footnotetext{
${ }^{12}$ We also exclude from the sample those individuals working less than 12 months in the previous year and earning less than six thousand euros gross, to minimize the impact of differences in months worked and to disregard workers less attached to the labour market
} 
(in eight dummies); education level: Primary, Secondary and Tertiary; having a Permanent vs a temporary job; having a full time vs a part time job; industry: Manufacturing, Wholesale, Restoration and Transport, Financial Intermediation and Business Activities, Public Administration, Education and Health, Others Services. ${ }^{13}$

Panel A of Table 11 includes the descriptive statistics for the sample of countries for which current gross (hourly) wages are available (AT, ES, GR, IE, IT, PT, UK). During the observed period female work participation increases pervasively, employees become, on average, more educated and slightly more experienced. The employment share in services increases, while manufacturing decreases. Temporary and part time contracts increase as well, consistently with the reforms concerning labour market flexibility adopted in many European countries in the last decades. As shown in Panel B of Table 11, the summary statistics remain similar when the wider sample of countries for which the yearly gross labour income for the previous year is available (AT, BE, DK, ES, FI, FR, GR, IE, IT, LU, PT, UK).

As for the technological proxies, we rely on the recent literature pointing out the importance of occupational level tasks (Autor et al., 2003; Goos and Manning, 2007; Lemieux, 2008). We consider three task measures at the occupation level, regarding Routine, Abstract and Service task intensity. Routine tasks are those that can be segmented in step-by-step rule. Non-routine tasks are split into two categories, Abstract and Service, to distinguish the cognitive skills required to complete these tasks. These measures are derived from Goos et al. (2014), that in turn used the Occupational Information Network (ONET) database. ${ }^{14}$

There is also an increasing interest in the impact of globalization on employment structure, i.e. outsourcing of parts of the production process focused on specific occupations (Feenstra and Hanson, 1999; Grossman and Rossi-Hansberg, 2008). For this reason we make use of another task variable concerning offshorability intensity, derived from Goos et al. (2014). ${ }^{15}$ All these

\footnotetext{
${ }^{13}$ See annex A for a detailed description of micro data and for variable definition.

${ }^{14}$ ONET is a comprehensive database which provides data on worker characteristics, worker requirements and general work activities in US occupations. As in Goos et al. (2014), the underlying assumption is that job characteristics are invariant across developed countries. See Goos et al. (2014) for further details about the computation of these occupational measures.

${ }^{15}$ Goos et al. (2014) derive this variable from the European Restructuring Monitor (ERM). For a recent analysis of the impact of trade and offshoring for the US labour market see Ebenstein et al. (2014).
} 
measures are available at the 2-digit International Standard Occupational Classification (ISCO), and we impute the corresponding value from Goos et al. (2009). Then, these variable has been normalized, as explained in Section 3.3.

Importantly, we can reproduce the finding concerning job polarizations of Goos et al. (2009) who use the European Labour Force Survey as a source of data. To do so, from the 2-digit ISCO88 classification we recover three aggregate occupation categories: top skilled, which include the 8 highest payed occupations; the medium skilled, with the 9 middling occupations; the unskilled, with the 4 lowest paying occupations. In the period 1996-2007, the share of hours worked in the top skilled occupations increased by 4.6 percentage points, decreased in the middling ones by 9.4 percentage points, and increased by 4.8 percentage points in the unskilled occupations. ${ }^{16}$

\subsection{Decomposition methodology}

We study the relation between technological and wage structure by conducting a counterfactual analysis by means of the decomposition methodology developed by Fortin et al. (2011). To grasp the intuition behind this methodology is useful to consider first the precursor of the wage decompositions, the so-called Oaxaca-Blinder decomposition of the difference in mean outcomes between two time periods (Blinder, 1973; Oaxaca, 1973).

Let $W_{t}$ denote the wage observed in two periods $t=\{0,1\}$ whose conditional expectation can be modeled as

$$
E\left[W_{t} \mid X_{t}\right]=\beta_{t 0}+X_{t}^{\prime} \beta_{t}
$$

where $X_{t i}=\left[X_{1 t}, X_{2 t}, \ldots, X_{K t}\right]$ is a $K \times 1$ vector of covariates. The overall difference in the average of $W$ between $t=1$ and $t=0$ can be written as

$$
\widehat{\Delta}_{O}^{\mu}=\underbrace{\left(\hat{\beta}_{10}-\hat{\beta}_{00}\right)+\sum_{k=1}^{K} \bar{X}_{k 1}\left(\hat{\beta}_{1}-\hat{\beta}_{0}\right)}_{\sum_{k=1}^{K} \Delta_{S, k}^{\mu}}+\underbrace{\sum_{k=1}^{K}\left(\bar{X}_{k 1}-\bar{X}_{k 0}\right) \hat{\beta}_{1}}_{\sum_{k=1}^{K} \Delta_{X, k}^{\mu}},
$$

\footnotetext{
${ }^{16}$ These changes are obtained using only observations for which data on current hourly wages is available. When the sample of the yearly gross earnings is used instead, the share of top occupations increased by 3.8 percentage points, the medium decreased by 8.8 percentage points and the lowest skilled ones increased by 5.0 percentage points.
} 
where $\bar{X}_{t}$ denotes the average of $X$ calculated on realizations from the $t$ period, and $\hat{\beta}_{10}, \hat{\beta}_{00}$, $\hat{\beta}_{0}$, and $\hat{\beta}_{1}$ are time specific OLS estimates of intercepts and coefficients for the two periods, respectively. The decomposition breaks down the overall difference in means into a component related to the changes in the returns of the set of covariates, the so called wage structure effect $\left(\Delta_{S}^{\mu}\right)$, and a component linked to the changes in the mean of these covariates, the so called composition effect $\left(\Delta_{X}^{\mu}\right)$. These effects are aggregate, because all the covariate are free to vary between periods. The wage structure and the composition effect can be broken down into the respective contribution of changes of each covariate, namely, $\Delta_{S, k}^{\mu}, \Delta_{X, k}^{\mu}, k=1, \ldots, K$.

The strict exogeneity condition implicit in (5) is not necessary for the identification of the two effects as it can be substituted with the less stringent ignorability assumption, which requires that the conditional expectation of residuals given $X$ is constant in the two time periods. If ignorability holds the decomposition has a casual interpretation (Fortin et al., 2011).

We are interested in decomposing the over time changes of percentiles of the wage distribution and changes of inequality indexes, such as the difference between the 90th and the 10th percentiles, between the 90th and the 50th, and between the 50th and the 10th. We can express the percentiles in terms of a functional $\nu$ that takes as argument the distribution of $W$, $\nu\left(F_{W}\right)$. To decompose $\nu\left(F_{W}\right)$ into a structure and a composition effect, both aggregate and detailed, we use the Re-centered Influence Function (RIF) regression method of Fortin et al. (2011). The method is an extension of the Oaxaca-Blinder decomposition that can be applied to non linear functionals. The only requirement is that the influence function of $\nu$ is available in closed form. ${ }^{17}$

The RIF-regression is similar to a standard regression, except that the dependent variable is replaced by the centered influence function of $\nu$ to which the decomposition is to be applied.

\footnotetext{
${ }^{17}$ The influence function (Hampel, 1974) is widely used to measure the robustness of a distributional statistic to the presence of outliers. The influence function detects the contribution (also defined as "influence") of each observation to the distributional parameter of interest. Formally, the influence function is

$$
I F(W, \nu)=\lim _{\epsilon \rightarrow 0} \frac{\nu\left(\epsilon G_{0}+(1-\epsilon) F_{W}\right)-\nu\left(F_{W}\right)}{\epsilon},
$$

where $G_{0}$ is a distribution which places all its probability mass to $W_{0}$, a point on the support of $W$. The influence function is available for many statistics of interest here, such as quantiles and other inequality indexes. Importantly, it holds that $\int I F(W, \nu) d F_{W}=0$.
} 
If $I F(W, \nu)$ denotes the influence function of $\nu$, the recenter influence function is given by

$$
R I F(W, \nu)=\nu\left(F_{W}\right)+I F(W, \nu) .
$$

Fortin et al. (2011) assume that the RIF can be modeled linearly

$$
\mathbb{E}\left[R I F\left(W_{t} ; \nu\right) \mid X_{t}\right]=X_{t} \beta_{t}^{\nu}, \quad t=0,1,
$$

where parameter $\beta^{\nu}$ represents the marginal effect of $X$ on $\nu$. Fortin et al. (2011) show that a decomposition of $\nu$ can be carried out by applying a Oaxaca-Blinder decomposition on the transformed data. For instance, $\beta_{t}^{\nu}$ can be estimated by OLS and changes in $\nu$ can be decomposed as

$$
\begin{aligned}
\widehat{\Delta}_{O}^{\nu} & =\bar{X}_{1}\left(\hat{\beta}_{1}^{\nu}-\hat{\beta}_{0}^{\nu}\right)+\left(\bar{X}_{1}-\bar{X}_{0}\right) \hat{\beta}_{0}^{\nu} \\
& =\widehat{\Delta}_{S}^{\nu}+\widehat{\Delta}_{X}^{\nu}
\end{aligned}
$$

The aggregate effects can be further decomposed into the detailed effect of each covariate:

$$
\begin{aligned}
\widehat{\Delta}_{S}^{\nu} & =\sum_{k=1}^{K} X_{1 k}^{\prime}\left(\hat{\beta}_{k, 1}^{\nu}-\hat{\beta}_{k, 0}^{\nu}\right) \\
\widehat{\Delta}_{X}^{\nu} & =\sum_{k=1}^{K}\left(X_{1 k}-X_{0 k}\right)^{\prime} \hat{\beta}_{0, k}^{\nu}
\end{aligned}
$$

The RIF-regression decomposition of $\nu$ can be biased since the linear specification holds only locally. ${ }^{18}$ The bias can be removed by reweighing the distribution of $X$ 's in period 0 to have the same distribution of period 1 . Let $X_{01}$ denote the reweighed version of the covariates. A regression of $R I F\left(W_{0}, \nu\right)$ on $X_{01}$ gives the counterfactual coefficient $\hat{\beta}_{01}^{\nu}$. One then estimates the reweighted composition effect $\hat{\Delta}_{X, R}^{\nu}$ as the sum of the "pure" composition effect, $\hat{\Delta}_{X, P}^{\nu}$, and of the specification error, $\hat{\Delta}_{X, e}^{\nu}$, which in turn captures the difference between the composition effect estimated using a non-parametric reweighting approach and the linear approximation obtained using the RIF-regressions:

$$
\hat{\Delta}_{X, R}^{\nu}=\underbrace{\left(\bar{X}_{01}-\bar{X}_{0}\right) \hat{\beta}_{0}^{\nu}}_{\hat{\Delta}_{X, P}^{\nu}}+\underbrace{\bar{X}_{01}\left[\hat{\beta}_{01}^{\nu}-\hat{\beta}_{0}^{\nu}\right]}_{\hat{\Delta}_{X, e}^{\nu}} .
$$

\footnotetext{
${ }^{18}$ This is not a specific problem with the RIF regression, but a rather general problem with decomposition techniques. As shown by Barsky et al. (2002), also the Oaxaca-Blinder decomposition for the mean change is biased.
} 
The reweighted wage structure effect is given by the sum of the "pure" wage structure effect, $\hat{\Delta}_{S, P}^{\nu}$, and of the reweighting error, $\hat{\Delta}_{S, e}^{\nu}$,

$$
\hat{\Delta}_{S, R}^{\nu}=\underbrace{\bar{X}_{1}\left[\hat{\beta}_{1}^{\nu}-\hat{\beta}_{01}^{\nu}\right]}_{\hat{\Delta}_{S, P}^{\nu}}+\underbrace{\left(\bar{X}_{1}-\bar{X}_{01}\right) \hat{\beta}_{01}^{\nu}}_{\hat{\Delta}_{S, e}^{\nu}} .
$$

In our subsequent analysis, we report the reweighed composition and structure effects. The reweighing scheme follows closely the one originally proposed by Di Nardo et al. (1996). The details of its implementation are given in the next section.

The interpretation of the detailed wage structure decomposition is often problematic due to the arbitrary choice of the base group (Oaxaca and Ransom, 1999). While is easier to identify a base group when dealing with categorical variables, the case of continuous covariates must be dealt with more care. Following Firpo et al. (2013) we normalize the continuous variables by using the following transformation

$$
\tilde{X}_{t}=X_{t}+\frac{\sigma_{X_{1}}}{2}-E\left(X_{1}\right)
$$

where $\sigma_{X_{1}}$ is the standard deviation of $X_{1}$. With this normalization the expectation of $\tilde{X}_{1}$ is equal to half the standard deviations of the covariates in the original unit of measure. While the normalization does not alter the composition effect, it has a re-scaling effect on the wage structure, which becomes:

$$
0.5 \cdot \frac{\sigma_{X_{1}}}{2}\left[\beta_{1}^{\nu}-\beta_{01}^{\nu}\right]
$$

This means that the wage structure effect have to be interpreted as the contribution to $\Delta_{O}^{\nu}$ of the structure effect associated with a half standard deviation increase in the value of $X_{1}$. In practice the normalization is applied by replacing expectations and standard deviations with sample counterparts.

\subsection{Decomposition results}

\subsubsection{Analysis for the decomposition of the dynamics of the gross current hourly wage}

We start by implementing the decomposition methodology in the time period 1996-2007 for the sample of seven European countries (AT, ES, GR, IE, IT, PT, UK) for which the dependent 
variable is the current gross hourly wage. ${ }^{19}$ We show the results of the decomposition methodology mainly by means of graphical representations, which we believe is the most effective way of summarizing the wealth of information produced by the decomposition applied at each decile of the wage distribution. Coefficients on the y-axis can be interpreted as log variations (in wages) between the beginning and end period.

Consistently with the descriptives statistics, Figure 5 shows that overall wages increase almost monotonically- along the distribution, entailing an increase in the $90-10$ index by $24.6 \%$. The decomposition allows separating the aggregate composition effect from the aggregate wage structure effect. It is worth noting that the wage structure effect drives in a sense the dynamics quite of the overall wage, while the composition effect is much flatter along the distribution. This is consistent to the US evidence, as pointed out by Firpo et al. (2013). ${ }^{20}$

We then move to the detailed composition and wage structure effects, to identify the impact of each set of covariates. Similarly to Firpo et al. (2013), we construct the following six components of interest, summing the coefficients for the variables included in each component:

- education

- technology (abstract, routine, service tasks)

- offshoring

- demographic (female and potential experience)

- institutions (part time and fixed term)

- sector

In Figure 6 we show the detailed composition effect. As first remark, all components are rather flat and very close to zero, meaning that they do not affect much the wage dynamics. As expected, technology has an increasing impact along the wage distribution although the

\footnotetext{
${ }^{19}$ The reference group is composed by male, with 20-25 years of experience, with upper secondary education, permanent and full time, in manufacturing. The same reference group will be used when considering the gross yearly earnings.

${ }^{20}$ The reweighing and specification errors, computed as defined in the methodological section, are very close to zero and not statistically significant. We report the two errors and their standard errors in Table 12.
} 
magnitude is very small. The effect of offshoring follows a similar pattern. Education is the variable with the strongest impact, although lower than 0.05 along the whole wage distribution). Rather surprisingly, the composition effect for education does not increase along the wage distribution, being indeed slightly decreasing. This is at odd to the US evidence, where the composition effect for education is increasing along the wage distribution (Firpo et al., 2013).

Figure 7 plots the detailed wage structure effect. The technological component entails a U-shape impact on wages: had only the coefficients associated to the technology component changed over time, wages would have polarized in the lower tail of the wage distribution, a consequence of the fact that the impact at the 10th and 20th percentiles (around $8 \%-10 \%$ ) is greater than the one at the median. The polarization of the upper part of the distribution is instead less pronounced.

We also decompose the technology component in the three occupational tasks (abstract, routine, service), as shown in Figure 8. Interestingly, the abstract component exerts a steep increasing impact along the wage distribution, entailing a positive impact on the increase of both the $90-50$ and the 50-10 ratios, even if in this latter case it is not statistically different from zero. As expected, returns from abstract task increase over time, especially for skilled workers in the upper tail of the distribution. Another very interesting finding concerns the pattern of the service task intensity, which is decreasing along the wage distribution. This means that had only the returns from service tasks changed over time, there would have been an increase in wages in the lower part of the wage distribution, with a polarization effect on the lower tail of the distribution that reduces the 50-10 ratio. This is consistent to what happened in the United States, where the polarization in the lower tail has been basically driven by the service sector and service tasks (Autor and Dorn, 2013; Mazzolari and Ragusa, 2013). A similar finding is observed for routine, although it is not statistically different from zero (see Table 12).

Another interesting pattern is associated to the education variable: had only the returns to education changed over time, wages would have decreased along all the wage distribution, with a peak around the 70th percentile (Figure 7). While been at odds with findings for the US, this is consistent with recent papers that observe falling returns to education in Spain (Izquierdo and Lacuesta, 2006), France (Charnoz et al., 2011), and Italy (Naticchioni et al., 2010), countries 
that are included in our sample. This is also consistent with the OECD (2011) finding that education entails a reducing impact on inequality trends in the last decades.

As far as the other components are concerned, they are almost all very close to zero and/or constant along the wage distribution, apart from the demographic component that displays an inverse U-shape pattern, favoring more individuals who are in the middle of the distribution (Figure 7).

In Table 12 we report the decomposition of the three standard inequality indexes (90-10, 90-50, 50-10) and the related standard errors, computed bootstrapping the whole procedure (100 replications).

In the industry level analysis we showed that the technological impact was mainly driven by the service sector, and in particular by the financial and postal-telecommunication industry. To investigate this issue using individual level data, we apply the decomposition analysis to the service sector. Figure 9 shows the detailed wage structure effect only for the service sector. The technological impact is similar to the one detected for the whole economy, with a u-shape patterns. Interestingly, this impact is stronger along the whole wage distribution, and especially in the lower tail of the distribution where the increase of the 10th percentile of the distribution is about $14 \%$, while it was about $8 \%$ for the whole economy. This evidence confirms that also using individual data the technological impact seems to play a major role in the service sector.

One might be worried about the possible role played by unobservables and general equilibrium effects, that we are unable to account for in our analysis. The effects of unobservables could be mitigated by using longitudinal data. Unfortunately, using the panel dimension of the EU SILC data would prohibitively reduce the sample size, due to its rotation scheme. Firpo et al. (2013), following Cortes (2014), make use of the londitudinal dimension of the PSID for the US to account for unobservables by means of occupation spell fixed effects, i.e., the interaction between individual fixed effects and occupation dummies. They point out that wage polarization dynamics is even more pronounced when controlling for unobservables. As for general equilibrium effects, they are likely to understate the impact of technology on changes in the wage distribution. In particular, occupation specific demand shocks should reduce wages for occupations not hit the shocks by shifting the supply of workers (Firpo et al., 2013). To sum up, 
overlooking the role of unobservables and of general equilibrium effects is likely to understate the contribution of occupation-specific demand effects to changes in the wage distribution. ${ }^{21}$

\section{Robustness checks}

As first robustness check we consider the current gross hourly wages in PPP. For sake of space we focus on the detailed wage structure effect, which represents the most interesting finding of the individual level analysis. Figure 10 shows the detailed wage structure effect when using gross current hourly wages in PPP. It emerges that trends are very close to the ones derived using wages not in PPP, with the main difference being that from the median to the top of the distribution the technological impact is constant while before it was slightly increasing. Also the decomposition of the technological tasks provide very similar findings (see Figure 11).

The second robustness check concerns the fact that in Europe there is an important heterogeneity concerning wage dynamics across countries, and that not controlling for this heterogeneity might affect the identification of the relation between wages and task measures. To deal with this issue we introduce in the RIF-regression country dummies as additional covariates, to control for all unobserved differences across countries. Figure 12 shows that introducing country dummies do not affect the wage structure impact of the technological component, which is even more U-shaped especially in the upper tail. Also the impact of the technological tasks does not change much (see Figure 13).

\subsubsection{Analysis for the decomposition of the dynamics of the gross yearly earnings}

Figure 14 shows the decomposition results for the sample of countries for which the gross yearly earnings are available (AT, BE, DK, ES, FI, FR, GR, IE, IT, LU, PT, UK). As already

\footnotetext{
${ }^{21}$ For the sake of space we do not report the over time changes of the intercept along the wage distribution. Note that it is close to zero at the ten percentile, slightly negative from the 20th to the 40th percentile and then it starts increasing up to the 90th percentile, playing a role in explaining the rise of the upper tail of the distribution. This is consistent with the idea that within group inequality increased over time especially at the top of the distribution, due to the role of unobservables (Lemieux, 2008). In accordance with Firpo et al. (2013) and Cortes (2014), we argue that unobservables might be a source of underestimation of technology impacts, especially in the upper part of the distribution where unobservables are increasing while the impact of technology is substantially constant.
} 
underlined in the descriptives statistics, the gross yearly earnings decreased in the lower tail of the distribution and increased in the upper tail, entailing an increase in earnings inequality.

As for the aggregate composition effect, it is much flatter -and always below- than the total change: had only the composition changed over time, wages would have increased much less than what observed. This also suggests that the wage structure effect has to be always greater than the total observed change, counterbalancing the composition effect. ${ }^{22}$

Among the components of the composition effect, Figure 15 shows that most of the patterns are close to those derived for the gross hourly wages. More specifically, the only positive component is education, which is constant along the wage distribution and anyway quite low in magnitude (at around 0.03), while the other components, apart institutions, are rather constant and very close to zero.

Interestingly, the main difference with respect to the gross hourly wages is that institutions is very important in the lower part of the distribution, representing the most important finding related to the composition effect. Had only the share of part time and temporary jobs increased over time, the lower tail of the wage distribution would have shift downward, strongly deteriorating the wages of unskilled workers at the 10th percentile and generating an increasing impact on the 50-10 ratio dynamics, ceteris paribus. This suggests that all the reforms introduced in the last 15 years in Europe aiming at increasing the labour market flexibility have entailed a negative wage impact in the lower part of the distribution. It is not surprising that the impact of institutions emerges when the gross yearly earnings are considered, while a milder impact is detected when using hourly wages.

This result is consistent with the OECD finding in (OECD, 2011), i.e., in developed countries the increase in flexibility have generated a positive impact on wage inequality, mainly through a negative impact in the lower tail of the distribution. However, these reforms might have exerted at the same time a negative impact on labour market inequality through a positive (negative) impact on employment (unemployment) rates. It is not easy to recover the prevailing effect,

\footnotetext{
${ }^{22}$ Also in this case both the reweighing and specification errors, computed as defined in the methodological section, are not statistically different from zero, even if especially in the upper tail of the distribution they amount to a non negligible -0.019 .
} 
i.e. whether the increase in flexibility has generated an overall positive or negative impact on labour market inequalities. This analysis goes beyond the goal of this paper.

As for the detailed wage structure effect, Figure (16), the patterns are close from a qualitative point of view to those observed for the sample of gross current wages. In particular, the technology component displays still a U-shape pattern, even if at the very top of the distribution it slightly decreases. When decomposing the three technological tasks, patterns are similar, with service (and routine) that drives the lower tail of the distribution, and with abstract that displays an increasing trends up to the 80th percentile, and then declines (Figure 17).

Consistently with the analysis on current hourly wages, the education component is slightly negative and constant along the distribution, confirming that in Europe education does not entail an increasing impact along the wage distribution. ${ }^{23}$

\section{Conclusions}

In this paper we investigate whether there are wage polarization trends at work in Europe. We study trends of unconditional wages as well as the conditional impact of technology on wages. We produce both an industry level and an individual level analysis. At the industry level, we use the WIOD and the EU KLEMS industry data for the period 1995-2007 for twelve European countries. As for unconditional wages, using industry data we find no evidence of wage polarization in Europe.

The evidence on the conditional wage polarization is more mixed. We find evidence that technological progress, as measured by the ICT intensity in capital compensation, has had an impact on job polarization through hours worked. However, we do not find evidence that wages have significantly responded in the same way to technology.

Since technological progress can affect within sector dynamics we also conduct an individual level analysis. We use harmonized micro data from two different sources, the ECHP data for 1996 and the EU-SILC data for 2007. Also using individual data, there is no evidence of unconditional wage polarization.

\footnotetext{
${ }^{23}$ We carried out the same robustness checks used for the gross hourly wages. Results confirms the main findings of the baseline specification. For sake of synthesis we do not include them in the text.
} 
To investigate the conditional wage polarization we augment the resulting dataset with task measures that proxy for the technological features of occupation (abstract, routine, service) and for the level of globalization (offshoring). We make use of two samples of countries, since we consider both gross hourly wages and gross yearly earnings. By applying the decomposition approach developed by Fortin et al. (2010), we show that while wage inequality has increased in Europe over the period considered, no signs of wage polarization are found. We point out that the wage structure related to technological task measures entails a U-shaped impact on the changes in the wage distribution, especially in the lower tail of the wage distribution. This U-Shaped impact is mainly due to the service task for the lower tail and to the abstract task for the upper tail of the distribution, while the impact of offshoring is constant along the wage distribution. Education has a negative impact on changes in inequality, consistently with OECD (2011); institutions play a role in accounting for the drop in the lower tail of the distribution of the gross yearly earnings. The other components (demographic, sector, education) are less relevant in accounting for increasing inequality. 


\section{References}

Acemoglu, D. And D. Autor (2011): "Skills, tasks and technologies: Implications for employment and earnings," Handbook of labor economics, 4, 1043-1171.

Antonczyk, D., T. DeLeire, And B. Fitzenberger (2010): "Polarization and rising wage inequality: comparing the US and Germany," ZEW-Centre for European Economic Research Discussion Paper.

AtKinson, A. (2008): The Changing Distribution of Earnings in OECD Countries, Oxford University Press.

Autor, D., L. Katz, And M. Kearney (2006): "The polarization of the US labor market," American Economic Review, 96, 189-194.

Autor, D., F. Levy, And R. Murnane (2003): "The Skill Content of Recent Technological Change: An empirical exploration," Quarterly Journal of Economics, 118, 1279-1333.

Autor, D. H. And D. Dorn (2013): "The Growth of Low Skill Service Jobs and the Polarization of the U.S. Labor Market," American Economic Review, 103, 1553-1597.

Barsky, R., J. Bound, K. Charles, and J. Lupton (2002): "Accounting for the blackwhite wealth gap," Journal of the American Statistical Association, 97, 663-673.

Bertola, G. And A. IChino (1995): "Wage inequality and unemployment: United States versus Europe," in NBER Macroeconomics Annual 1995, Volume 10, MIT Press, 13-66.

Blinder, A. (1973): "Wage discrimination: reduced form and structural estimates," Journal of Human resources, 8, 436-455.

Blinder, A. S. (2009): "Offshoring: Big Deal, or Business as Usual?" Offshoring of American jobs. What response from US economic policy, 19-60.

Centeno, M. And Ä. Novo (2009): When supply meets demand: Wage inequality in Portugal, IZA no.4592. 
Charnoz, P., E. Coudin, And M. Gaini (2011): "Wage inequalities in France 1976-2004: a quantile regression analysis," INSEE working paper, no.6.

Cortes, G. M. (2014): "Where Have the Middle-Wage Workers Gone? A Study of Polarization using Panel Data," Forthcoming in Journal of Labor Economics.

Di Nardo, J., N. Fortin, And T. Lemieux (1996): "Labor market institutions and the distribution of wages, 1973-1993: a semi-parametric approach," Econometrica, 64, 1001-1044.

Dustmann, C., J. Ludsteck, And U. Schnberg (2008): "Revisiting the German Wage Structure," Quarterly Journal of Economics, 142, 843-881.

Ebenstein, A., A. Harrison, M. M., And S. Phillips (2014): "Estimating the Impact of Trade and Offshoring on American Workers Using the Current Population Surveys," forthcoming in the Review of Economics and Statistics, 19-34.

Feenstra, R. and G. Hanson (1999): "The Impact of Outsourcing and High-Technology Capital on Wages: Estimates For The United States, 1979-1990," Quarterly Journal of Economics, 114, 907-940.

Firpo, S., N. Fortin, And T. Lemieux (2013): "Occupational Tasks and Changes in the Wage Structure," available at http://www.economics.ubc.ca/faculty-and-staff/thomaslemieux/, revised and resubmitted to American Economic Review.

Fortin, N., S. Firpo, And T. Lemieux (2010): "Decomposition methods in economics," NBER Working Paper, published in Handbook of Labor Economics, Elsevier, 2011.

Fortin, N., T. Lemieux, And S. Firpo (2011): "Decomposition methods in economics," Handbook of Labor Economics, 4, 1-102.

Frick, J. AND K. Krell (2010): "Measuring Income in Household Panel Surveys for Germany: A Comparison of EU-SILC and SOEP," SOEP papers on Multidisciplinary Panel Data Research, 265.

Goos, M. And A. Manning (2007): "Lousy and lovely jobs: The rising polarization of work in Britain," The Review of Economics and Statistics, 89, 118-133. 
Goos, M., A. Manning, And A. Salomons (2009): "Job polarization in Europe," American Economic Review, 99, 58-63.

(2014): "Explaining Job Polarization in Europe: The Roles of Technology and Globalization," Tech. rep.

Grossman, G. And E. Rossi-Hansberg (2008): "Trading tasks: a simple theory of offshoring," American Economic Review, 98, 1978-1997.

HAMPEL, F. (1974): "The influence curve and its role in robust estimation," Journal of the American Statistical Association, 69, 383-393.

Hauser, R. (2008): "Problems of the German Contribution to EU-SILC: A research perspective, compar ing EU-SILC, Microcensus and SOEP," German Council for Social and Economic Data (RatSWD), 80.

Izquierdo, M. AND A. Lacuesta (2006): "Wage inequality in Spain: Recent developments," Banco de Espana working paper, no.615.

Krugman, P. (1994): "Europe jobless, America penniless?” Foreign Policy, 19-34.

Lemieux, T. (2008): "The changing nature of wage inequality," Journal of Population Economics, 21, 21-48.

Machin, S. (2011): "Changes in UK Wage Inequality Over the Last Forty Years," in P. Gregg and J. Wadsworth (eds.) The Labour Market in Winter - The State of Working Britain.

Mazzolari, F. AND G. Ragusa (2013): "Spillovers from high-skill consumption to low-skill labor markets," Review of Economics and Statistics, 95, 74-86.

Michaels, G., A. Natraj, And J. Van Reenen (2013): "Has ICT Polarized Skill Demand? Evidence from Eleven Countries over 25 years," forthcoming in the Review of Economics and Statistics.

Naticchioni, P., A. Ricci, and E. Rustichelli (2008): "Wage inequality, employment structure and skill-biased change in Italy," Labour, 22, 27-51. 
(2010): "Far away from a skill-biased change: falling educational wage premia in Italy," Applied Economics, 42, 3383-3400.

OAXACA, R. (1973): "Male-female wage differentials in urban labor markets," International Economic Review, 14, 693-709.

OAXACA, R. And M. Ransom (1999): "Identification in detailed wage decompositions," Review of Economics and Statistics, 81, 154-157.

OECD (2011): Divided We Stand: Why Inequality Keeps Rising, OECD Publishing.

O’Mahony, M. and M. P. Timmer (2009): "Output, Input and Productivity Measures at the Industry Level: The EU KLEMS Database*," The Economic Journal, 119, F374-F403.

Timmer, M. P. (2012): "The World Input-Output Database (WIOD): Contents, Sources and Methods," WIOD Background document available at www.wiod.org. 


\section{Figures and Tables}

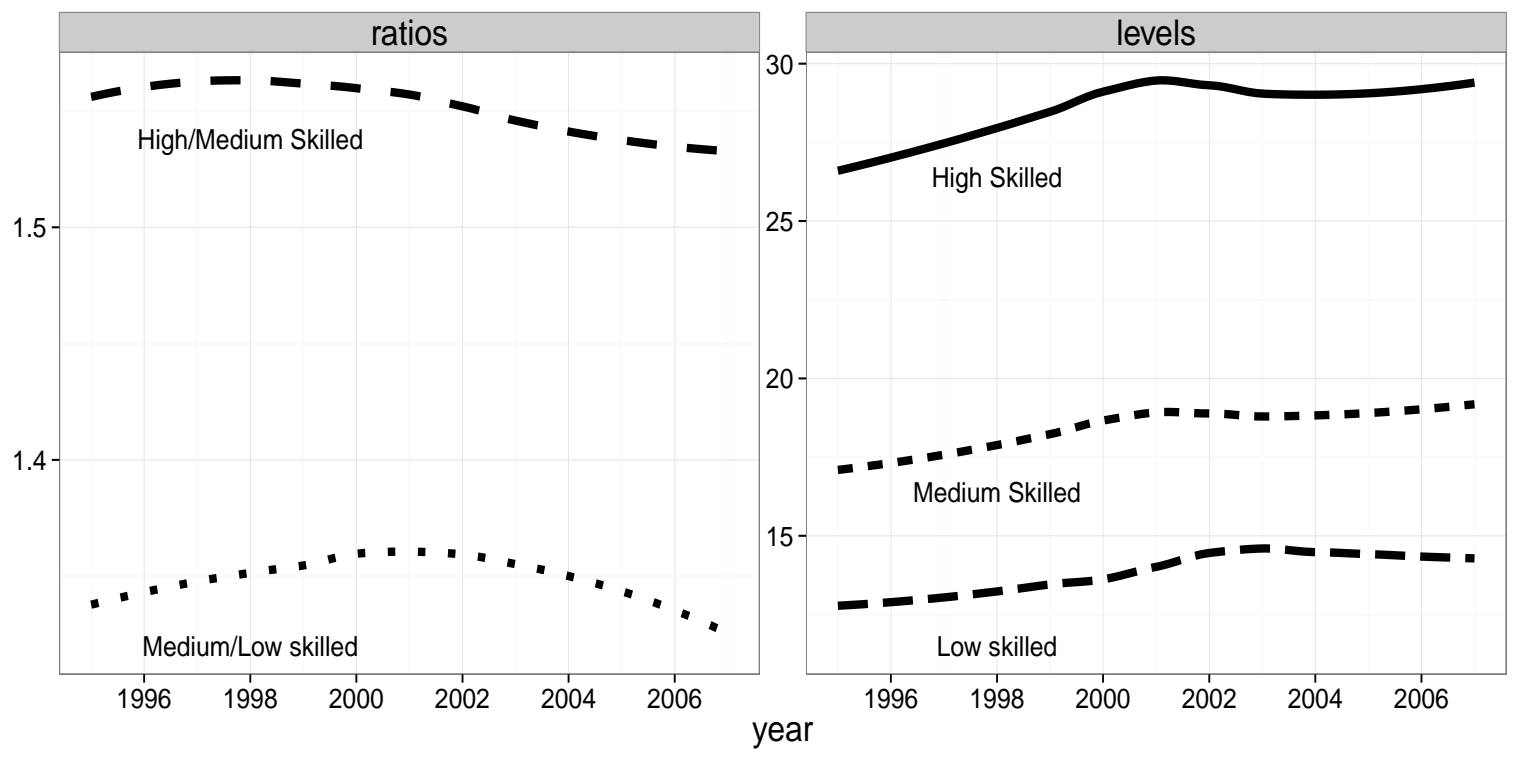

Figure 1: The left panel plots the ratio of high skilled wages to medium skilled wages and the ratio of medium skilled wages to low skilled wages and the ration over the period 1995-2007. The right panel plots wages for the three skill groups. Wage figures are obtained by aggregating Wiod data over countries and industries. 


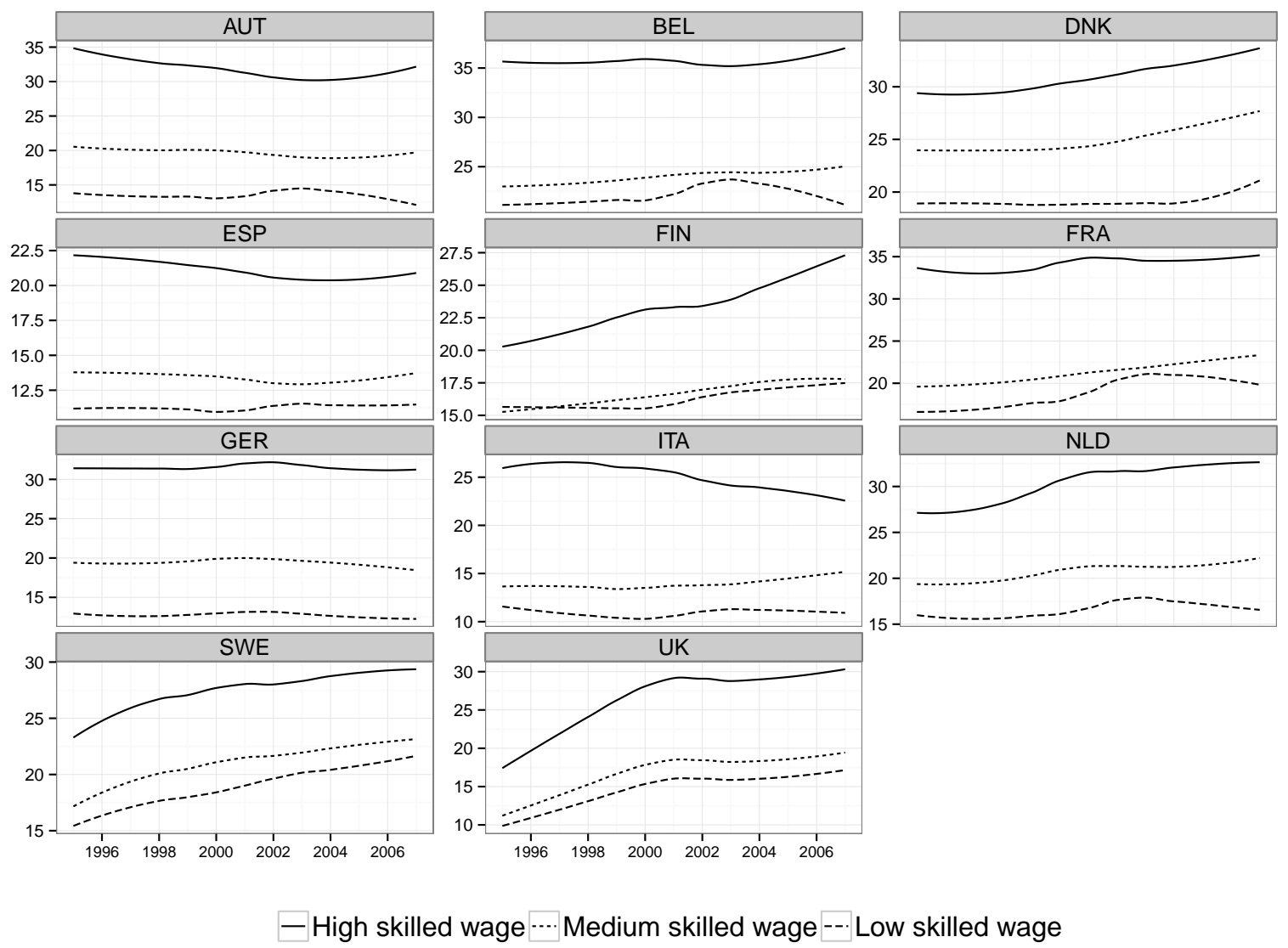

Figure 2: Each panel plots the dynamic of real wages for the three skilled groups. Wage figures are obtained by aggregating Wiod data over industries. 


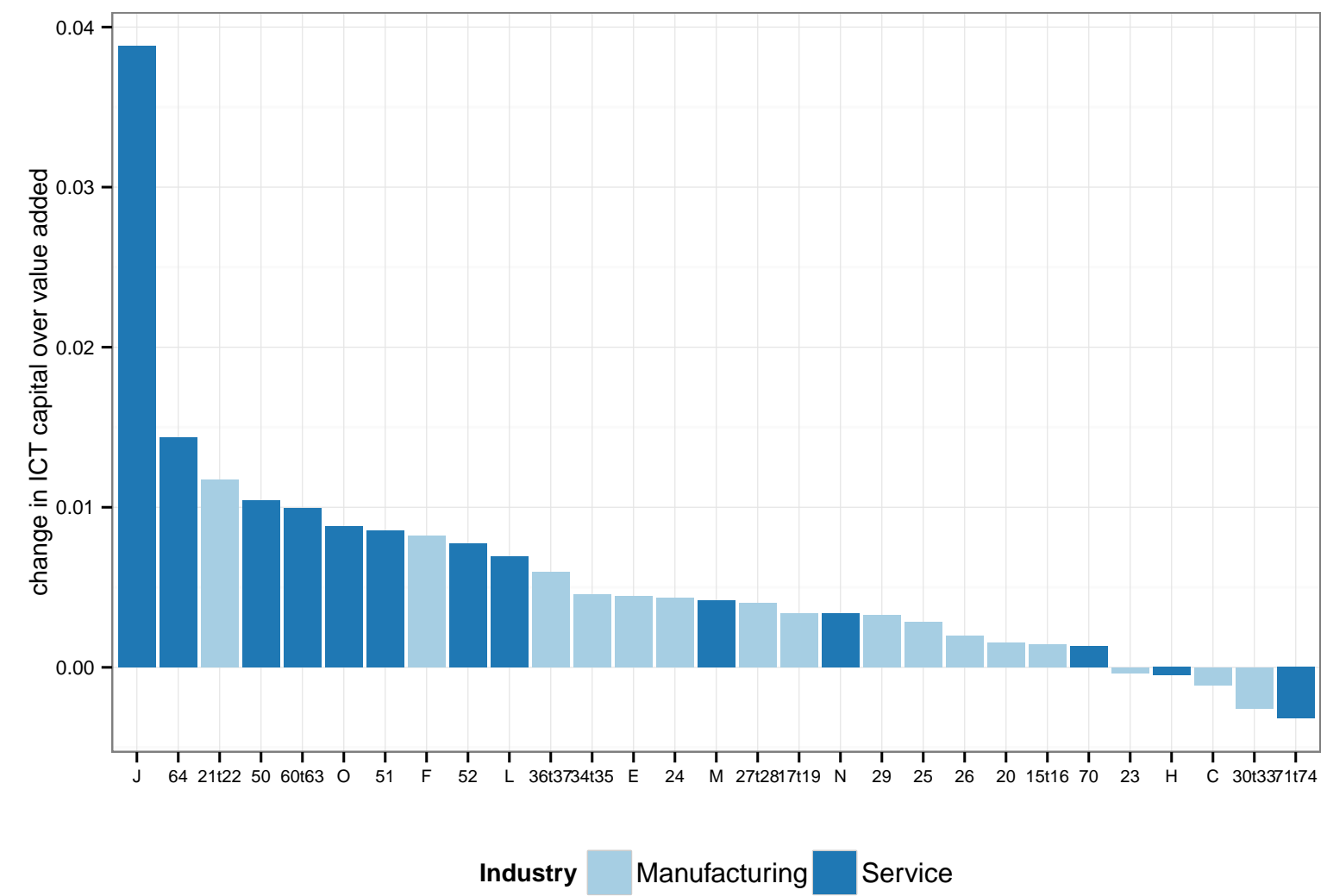

Figure 3: Aggregate by-industry 1995-2007 changes in ICT capital compensation over value added. Industries are divided in Service and Manufacturing. Country data are aggregated using as weights the 1995 share of each country and code's employment. 


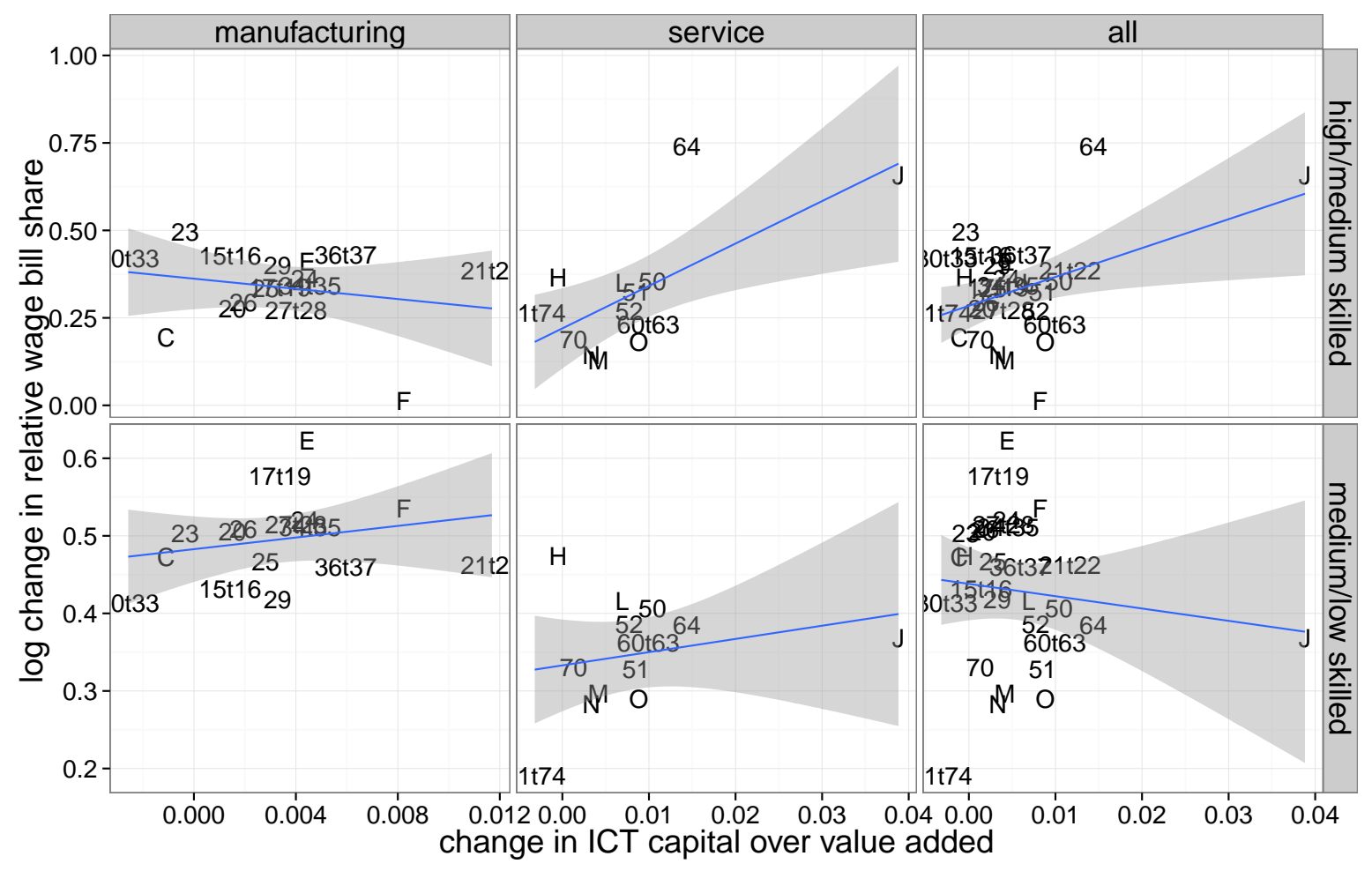

Figure 4: ICT capital compensation and labor bill share. Each column plots the 19952007 changes in ICT capital over value added and changes in the ratio of wage bill shares. The top panel plots the high to medium skilled bill share; the bottom panel the medium to low skilled wage bill share. Aggregate data for the available countries are obtained by aggregating data on ICT capital, labor compensation, and hours worked by skill levels over country cells. 


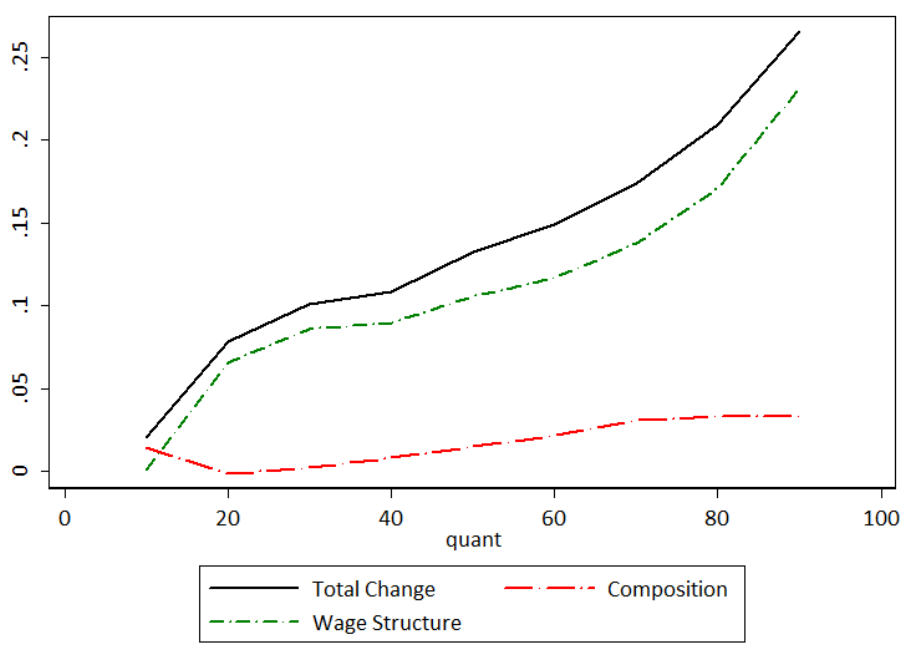

Figure 5: Gross current hourly wage: overall change, aggregate composition and wage structure effects. Sample of countries for which hourly wages are available (AT, ES, GR, IE, IT, PT, UK).

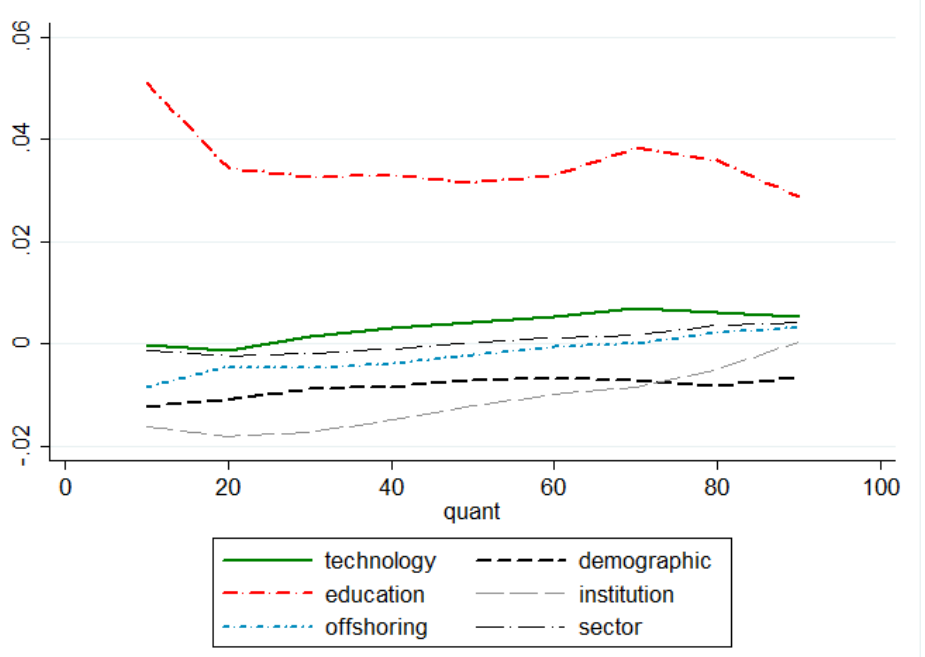

Figure 6: Gross current hourly wage: detailed composition effect. Sample of countries for which hourly wages are available (AT, ES, GR, IE, IT, PT, UK). 


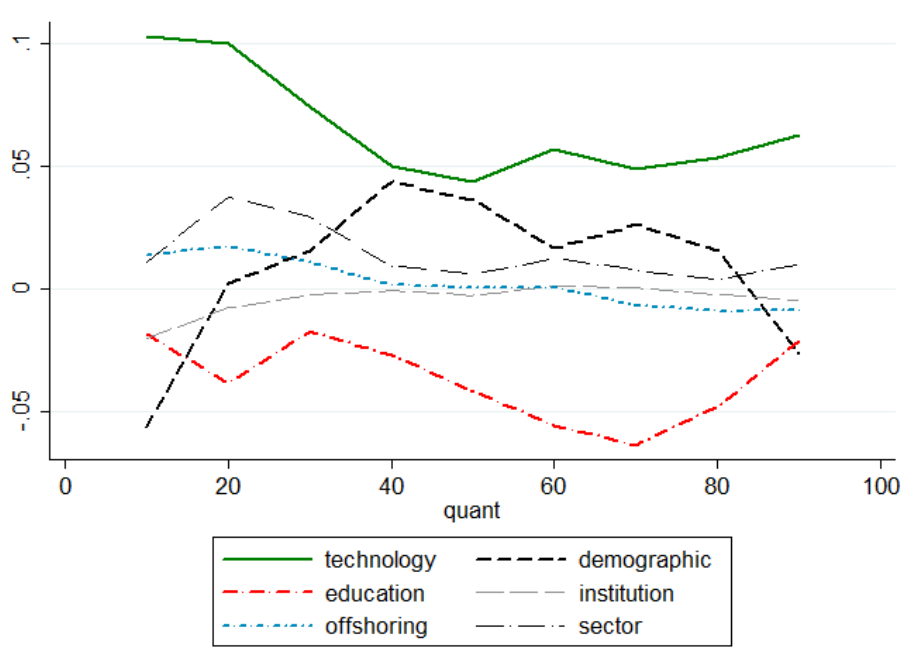

Figure 7: Gross current hourly wage: Detailed wage structure effect. Sample of countries for which hourly wages are available (AT, ES, GR, IE, IT, PT, UK).

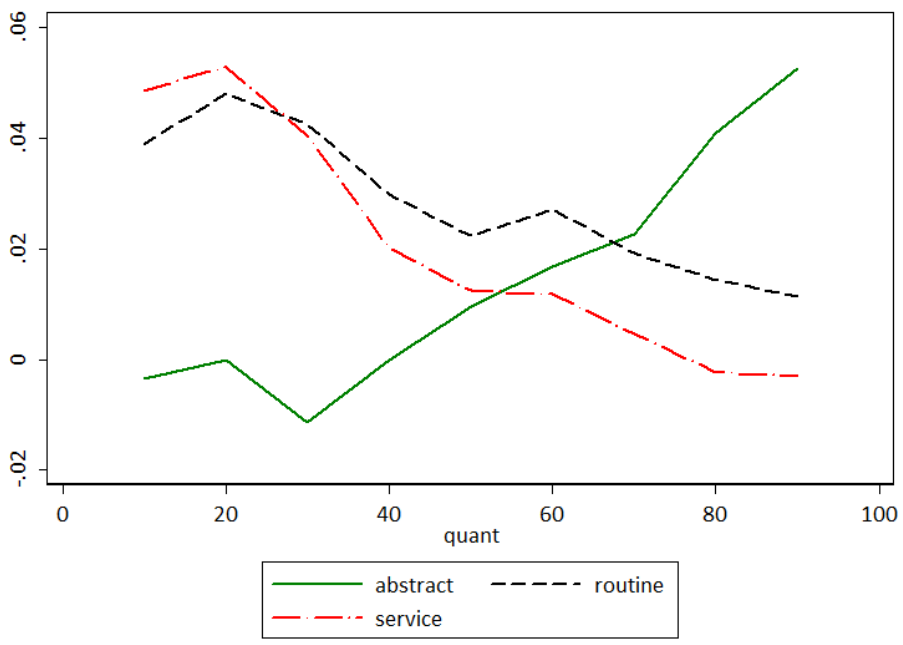

Figure 8: Gross current hourly wage: Wage structure effect for abstract, routine and service tasks. Sample of countries for which hourly wages are available (AT, ES, GR, IE, IT, PT, UK). 


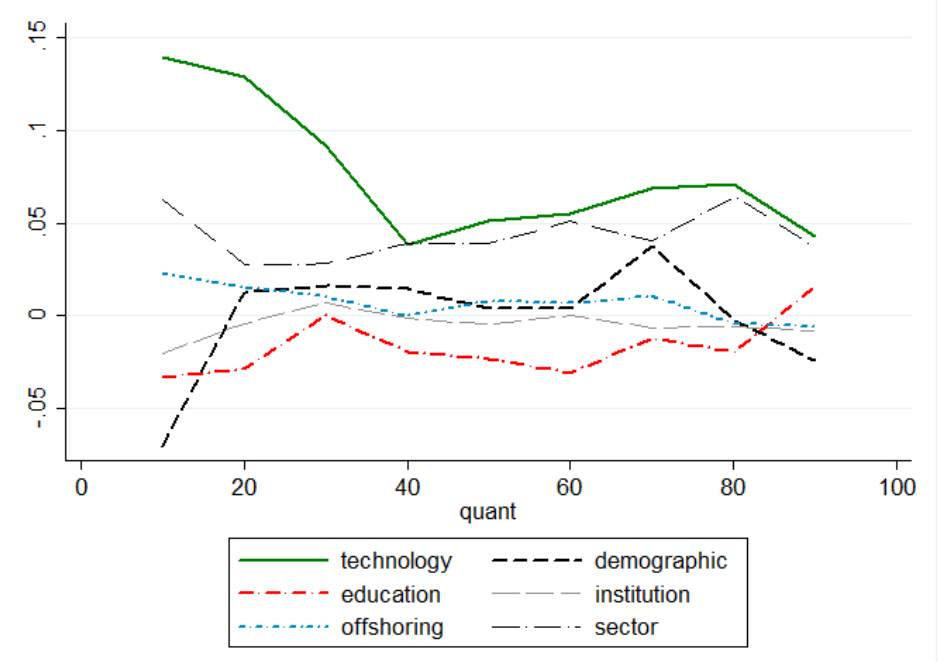

Figure 9: Gross current hourly wages: detailed wage structure effect in the service sector. Sample of countries for which hourly wages are available (AT, ES, GR, IE, IT, PT, UK).

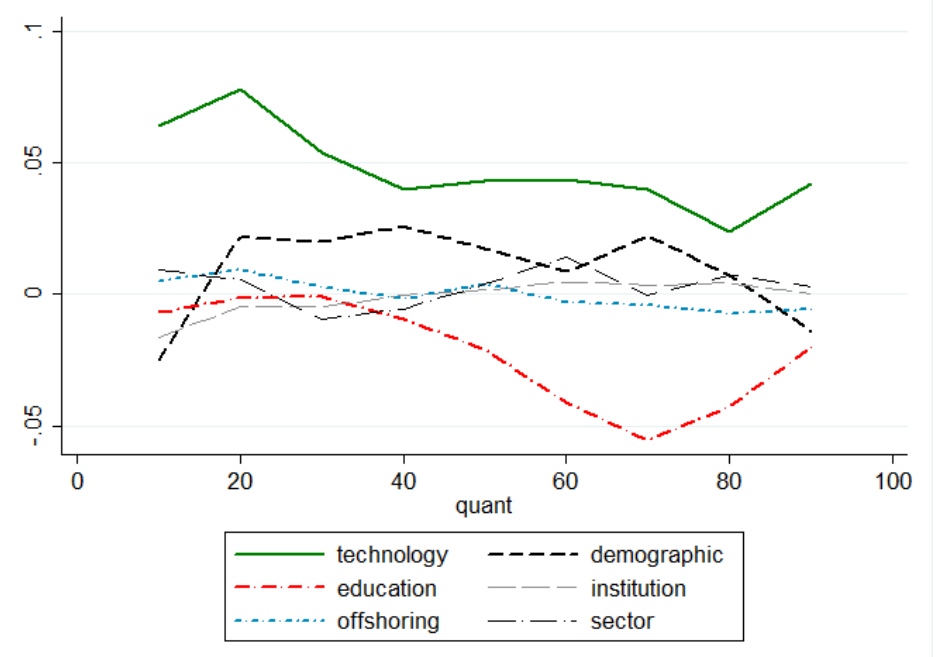

Figure 10: Gross current hourly wages in PPP: detailed wage structure effect. Sample of countries for which hourly wages are available (AT, ES, GR, IE, IT, PT, UK). 


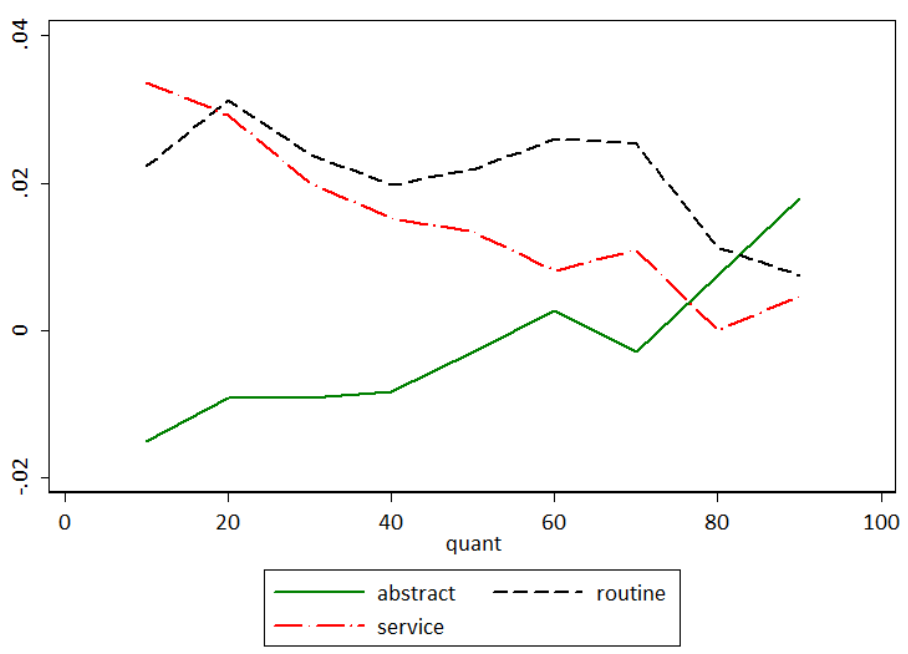

Figure 11: Gross current hourly wages in PPP: Wage structure effect for abstract, routine and service tasks. Sample of countries for which hourly wages are available (AT, ES, GR, IE, IT, PT, UK).

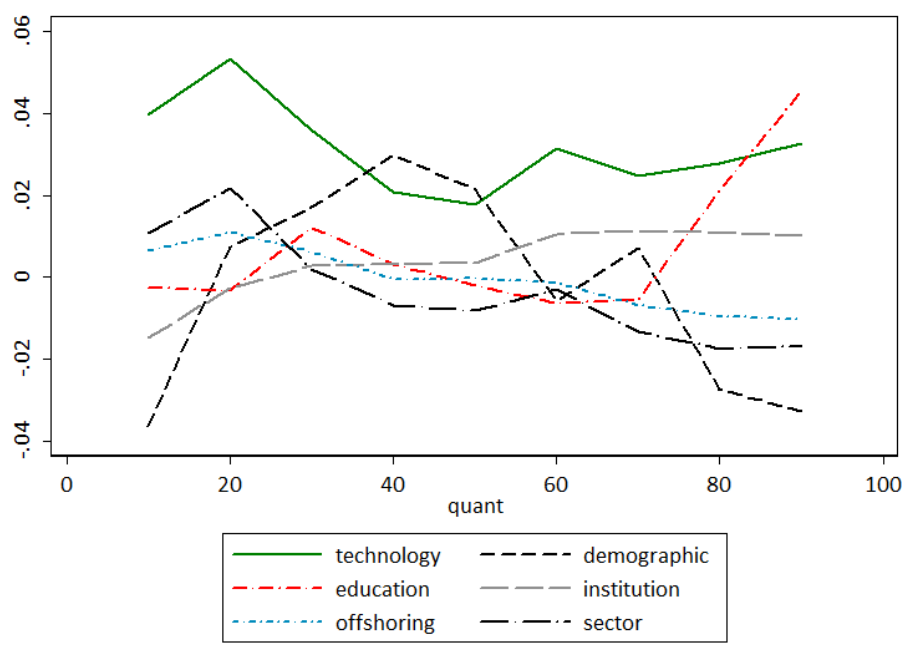

Figure 12: Gross current hourly wages: detailed wage structure effect with country dummies. Sample of countries for which hourly wages are available (AT, ES, GR, IE, IT, PT, UK). 


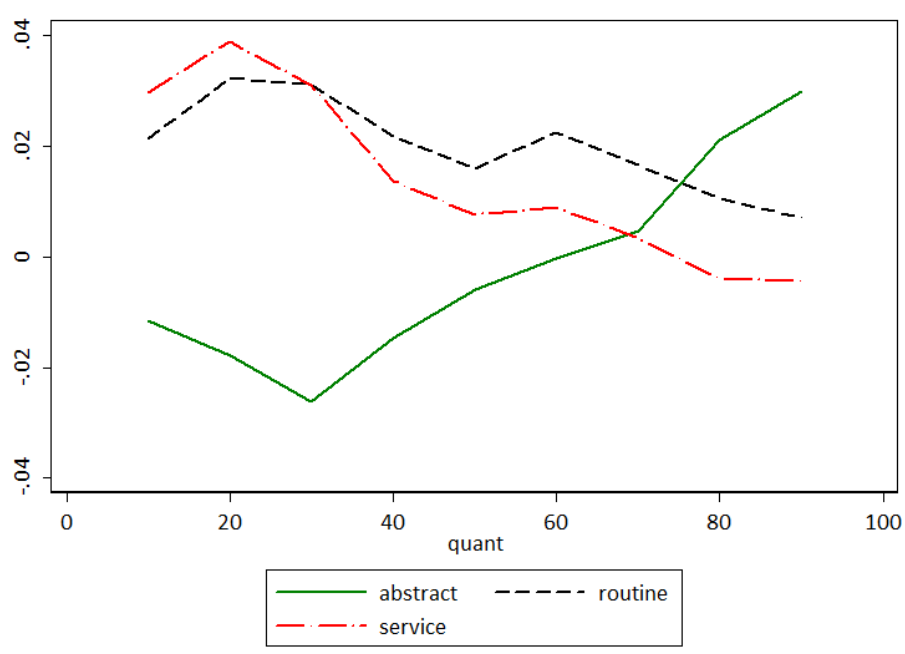

Figure 13: Gross current hourly wages: wage structure effect for abstract, routine and service tasks, with country dummies. Sample of countries for which hourly wages are available (AT, ES, GR, IE, IT, PT, UK).

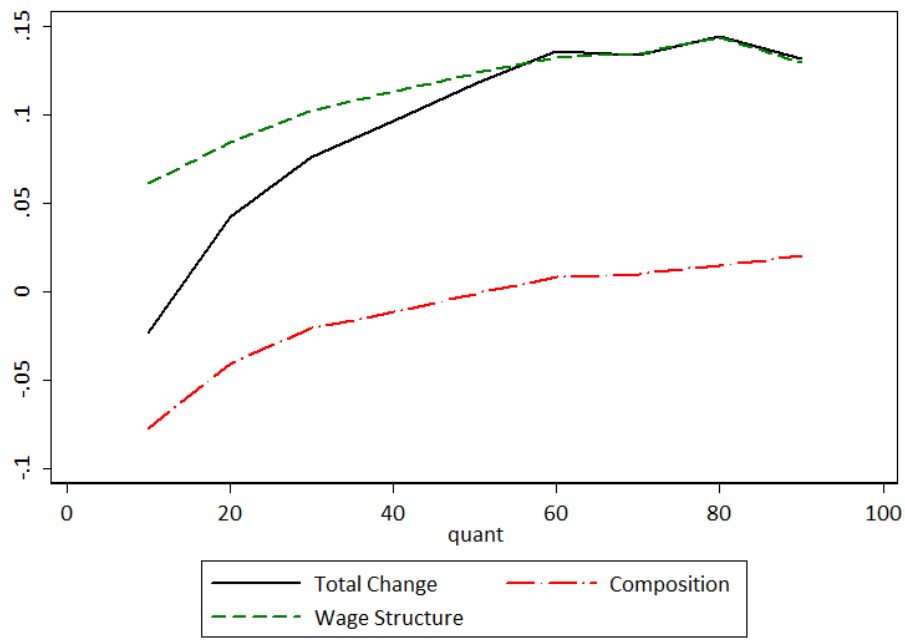

Figure 14: Gross yearly earnings: overall change, aggregate composition and wage structure effects. Sample of countries for which the gross yearly earnings are available (AT, BE, DK, ES, FI, FR, GR, IE, IT, LU, PT, UK). 


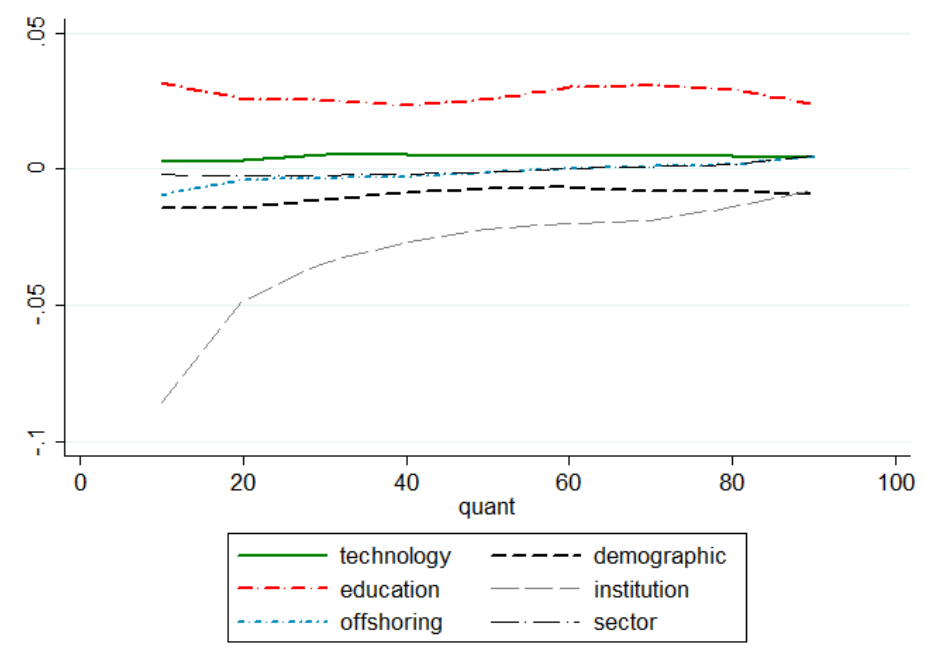

Figure 15: Gross yearly earnings: detailed composition effect. Sample of countries for which the gross yearly earnings are available (AT, BE, DK, ES, FI, FR, GR, IE, IT, LU, PT, UK).

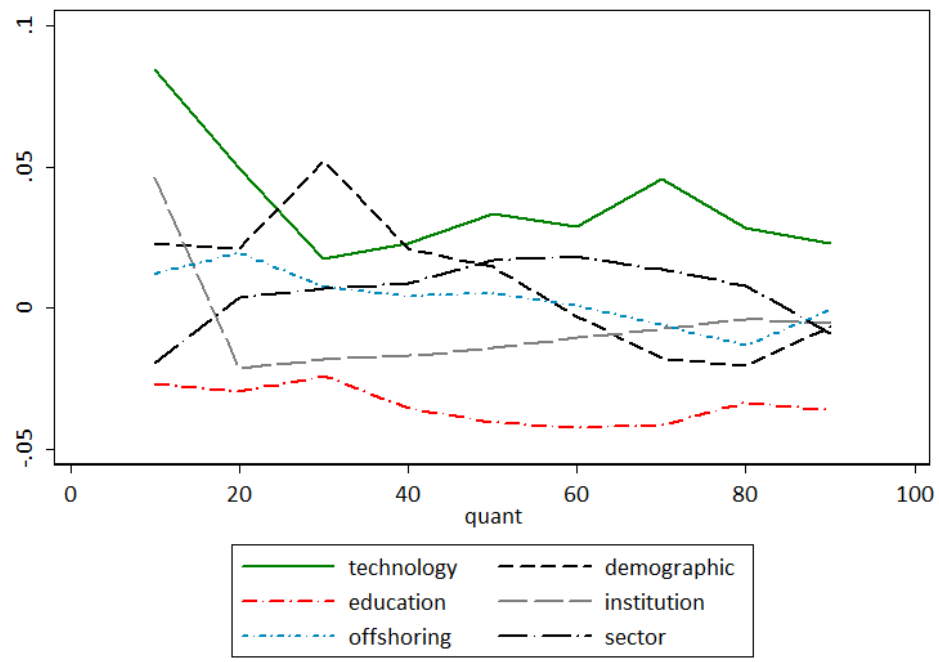

Figure 16: Gross yearly earnings: detailed wage structure effect. Sample of countries for which the gross yearly earnings are available (AT, BE, DK, ES, FI, FR, GR, IE, IT, LU, PT, UK). 


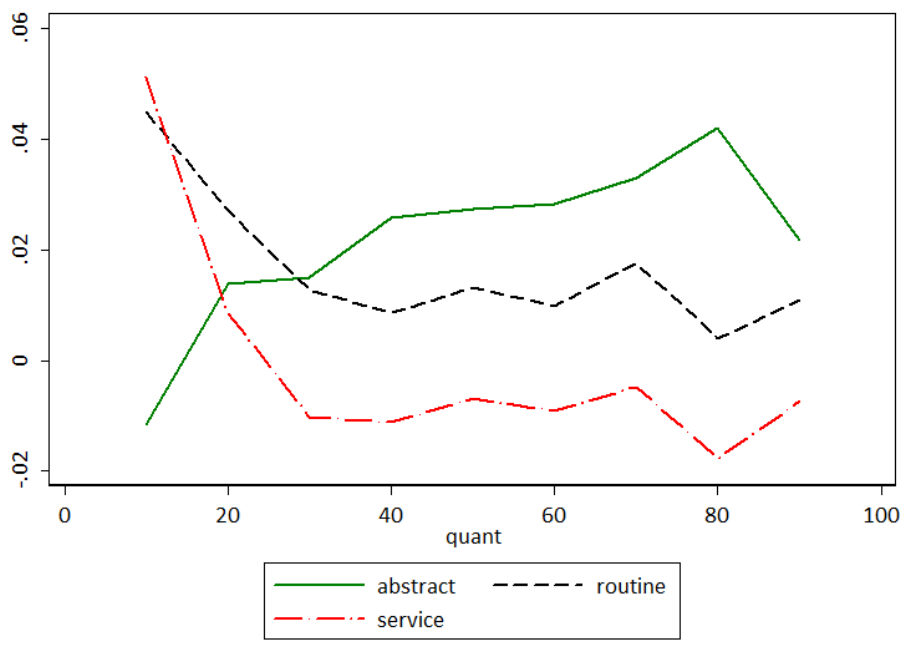

Figure 17: Gross yearly earnings: wage structure effect for abstract, routine and service tasks. Sample of countries for which the gross yearly earnings are available (AT, BE, DK, ES, FI, FR, GR, IE, IT, LU, PT, UK). 


\begin{tabular}{|c|c|c|}
\hline Description & Nace Code & Manufacturing \\
\hline Basic Metals and Fabricated Metal & $27 \mathrm{t} 28$ & Yes \\
\hline Chemicals and Chemical Products & 24 & Yes \\
\hline Coke, Refined Petroleum and Nuclear Fuel & 23 & Yes \\
\hline Construction & $\mathrm{F}$ & Yes \\
\hline Electrical and Optical Equipment & $30 \mathrm{t} 33$ & Yes \\
\hline Electricity, Gas and Water Supply & $\mathrm{E}$ & Yes \\
\hline Food, Beverages and Tobacco & $15 \mathrm{t} 16$ & Yes \\
\hline Machinery, Nec & 29 & Yes \\
\hline Manufacturing, Nec; Recycling & $36 \mathrm{t} 37$ & Yes \\
\hline Mining and Quarrying & $\mathrm{C}$ & Yes \\
\hline Other Non-Metallic Mineral & 26 & Yes \\
\hline Pulp, Paper, Paper, Printing and Publishing & $21 \mathrm{t} 22$ & Yes \\
\hline Rubber and Plastics & 25 & Yes \\
\hline Textiles and Textile Products & $17 \mathrm{t} 19$ & Yes \\
\hline Transport Equipment & $34 \mathrm{t} 35$ & Yes \\
\hline Wood and Products of Wood and Cork & 20 & Yes \\
\hline Education & M & \\
\hline Financial Intermediation & $\mathrm{J}$ & \\
\hline Health and Social Work & $\mathrm{N}$ & \\
\hline Hotels and Restaurants & $\mathrm{H}$ & \\
\hline Inland Transport & $60 \mathrm{t} 63$ & \\
\hline Other Community, Social and Personal Services & $\mathrm{O}$ & \\
\hline Post and Telecommunications & 64 & \\
\hline Public Admin and Defence; Compulsory Social Security & $\mathrm{L}$ & \\
\hline Real Estate Activities & 70 & \\
\hline Renting of Equipment and Other Business Activities & $71 \mathrm{t} 74$ & \\
\hline Retail Trade, Except of Motor Vehicles; Repair of Household Goods & 52 & \\
\hline Sale, Maintenance and Repair of Motor Vehicles Retail Sale of Fuel & 50 & \\
\hline Wholesale Trade and Commission Trade, Except of Motor Vehicles & 51 & \\
\hline
\end{tabular}

Table 1: Description of NACE classification codes resulting from the harmonization of WIOD and EU KLEMS. 


\begin{tabular}{|c|c|c|c|c|c|c|c|c|}
\hline \multirow[t]{2}{*}{ Country } & \multicolumn{8}{|c|}{ 1995-2007 } \\
\hline & $\Delta \ln \frac{B S_{H S}}{B S_{M S}}$ & $\Delta \ln \frac{B S_{M S}}{B S_{L S}}$ & $\Delta \ln \frac{N^{H S}}{N^{M S}}$ & $\Delta \ln \frac{N^{M S}}{N^{L S}}$ & $\Delta \ln \frac{W^{H S}}{W^{M S}}$ & $\Delta \ln \frac{W^{M S}}{W^{L S}}$ & $\Delta \ln \frac{K_{I C T}}{V A}$ & $\Delta \ln \frac{K_{N I C T}}{V A}$ \\
\hline AUT & 0.39 & 0.26 & 0.47 & 0.29 & -0.01 & 0.07 & 0.176 & 0.050 \\
\hline BEL & -0.06 & 0.74 & 0.08 & 0.64 & -0.02 & 0.06 & 0.036 & 0.212 \\
\hline DNK & 0.39 & -0.34 & 0.38 & -0.32 & -0.03 & -0.01 & 0.410 & -0.036 \\
\hline ESP & -0.12 & 0.75 & -0.04 & 0.79 & -0.11 & -0.03 & 0.149 & 0.280 \\
\hline FIN & 0.13 & 0.53 & 0.09 & 0.53 & 0.13 & 0.01 & 0.145 & 0.084 \\
\hline FRA & 0.08 & 0.45 & 0.21 & 0.43 & -0.16 & -0.03 & 0.074 & 0.047 \\
\hline GER & 0.21 & -0.05 & 0.23 & -0.01 & 0.06 & -0.06 & 0.104 & 0.083 \\
\hline IRE & 0.56 & 0.36 & 0.44 & 0.49 & 0.18 & 0.05 & -0.190 & 0.447 \\
\hline ITA & -0.07 & 0.75 & 0.28 & 0.56 & -0.32 & 0.18 & 0.069 & 0.089 \\
\hline NLD & 0.43 & 0.19 & 0.48 & 0.15 & -0.01 & 0.04 & 0.191 & 0.044 \\
\hline SWE & 0.33 & 0.40 & 0.45 & 0.44 & -0.13 & -0.06 & 0.109 & 0.156 \\
\hline UK & 0.24 & 0.56 & 0.25 & 0.59 & -0.02 & -0.01 & 0.191 & 0.053 \\
\hline \multirow[t]{2}{*}{ Country } & \multicolumn{8}{|c|}{1995} \\
\hline & $\frac{B S_{H S}}{B S_{M S}}$ & $\frac{B S_{M S}}{B S_{L S}}$ & $\frac{N^{H S}}{N^{M S}}$ & $\frac{N^{M S}}{N^{L S}}$ & $\frac{W^{H S}}{W^{M S}}$ & $\frac{W^{M S}}{W^{L S}}$ & $\frac{K_{I C T}}{V A}$ & $\frac{K_{N I C T}}{V A}$ \\
\hline AUT & 0.27 & 3.78 & 0.17 & 2.36 & 1.55 & 1.39 & 0.022 & 0.232 \\
\hline BEL & 0.44 & 1.41 & 0.33 & 1.54 & 1.52 & 1.08 & 0.037 & 0.210 \\
\hline DNK & 0.54 & 2.93 & 0.59 & 2.54 & 1.28 & 1.22 & 0.045 & 0.204 \\
\hline ESP & 1.93 & 0.27 & 1.27 & 0.23 & 1.50 & 1.17 & 0.029 & 0.268 \\
\hline FIN & 0.95 & 1.55 & 0.73 & 1.66 & 1.30 & 0.99 & 0.028 & 0.164 \\
\hline FRA & 0.85 & 1.29 & 0.64 & 1.15 & 1.65 & 1.14 & 0.024 & 0.232 \\
\hline GER & 0.56 & 5.65 & 0.37 & 3.98 & 1.63 & 1.49 & 0.012 & 0.178 \\
\hline IRE & 0.67 & 1.02 & 0.51 & 0.81 & 1.29 & 1.05 & 0.017 & 0.242 \\
\hline ITA & 0.42 & 0.60 & 0.26 & 0.61 & 1.82 & 0.99 & 0.018 & 0.221 \\
\hline NLD & 0.55 & 1.71 & 0.49 & 1.59 & 1.39 & 1.19 & 0.031 & 0.200 \\
\hline SWE & 0.47 & 2.46 & 0.43 & 2.72 & 1.48 & 1.11 & 0.033 & 0.185 \\
\hline UK & 0.84 & 1.41 & 0.66 & 1.29 & 1.60 & 1.15 & 0.040 & 0.189 \\
\hline
\end{tabular}

Table 2: The top panel shows log changes of relative wage bill share, relative hours worked, relative wages and the level differences in ICT and non-ICT capital intensity over the 1995-2007 period. The bottom panel reports by-country means of relative wage bill share, relative hours worked, relative wages, ICT and non-ICT capital intensity $\left(K_{N I C T} / V A\right)$ in 1995. 


\begin{tabular}{|c|c|c|c|c|c|c|}
\hline & (1) & $(2)$ & $(3)$ & (4) & $(5)$ & (6) \\
\hline VARIABLES & $\Delta \ln \left(\frac{B S^{H}}{B S^{M}}\right)$ & $\Delta \ln \left(\frac{N^{H}}{N^{M}}\right)$ & $\Delta \ln \left(\frac{W^{H}}{W^{M}}\right)$ & $\Delta \ln \left(\frac{B S^{M}}{B S^{L}}\right)$ & $\Delta \ln \left(\frac{N^{M}}{N^{L}}\right)$ & $\Delta \ln \left(\frac{W^{M}}{W^{L}}\right)$ \\
\hline \multirow[t]{2}{*}{$\Delta K / Q$} & $2.283^{* * *}$ & $1.793^{* * *}$ & 0.489 & $-2.707^{* * *}$ & $-2.034^{* * *}$ & -0.673 \\
\hline & $(0.748)$ & $(0.662)$ & $(0.361)$ & $(0.973)$ & $(0.774)$ & $(0.408)$ \\
\hline \multirow[t]{2}{*}{$\Delta C / Q$} & 0.187 & -0.0468 & 0.233 & -0.303 & -0.428 & 0.125 \\
\hline & $(0.222)$ & $(0.220)$ & $(0.168)$ & $(0.376)$ & $(0.316)$ & $(0.142)$ \\
\hline \multirow[t]{2}{*}{$\Delta \ln (Q)$} & $-0.217^{* * *}$ & $-0.147^{* *}$ & $-0.0698^{*}$ & $0.361^{* * *}$ & $0.352^{* * *}$ & 0.00894 \\
\hline & $(0.0699)$ & $(0.0659)$ & $(0.0394)$ & $(0.0812)$ & $(0.0757)$ & $(0.0406)$ \\
\hline \multirow[t]{2}{*}{$(K / Q)_{1995}$} & $2.384^{* * *}$ & $1.850^{* * *}$ & $0.534^{*}$ & -0.450 & -0.240 & -0.210 \\
\hline & $(0.649)$ & $(0.578)$ & $(0.282)$ & $(0.813)$ & $(0.594)$ & $(0.350)$ \\
\hline \multirow[t]{2}{*}{$(K / Q)_{1995}$} & -0.0989 & 0.0629 & $-0.162^{*}$ & 0.0991 & -0.0316 & 0.131 \\
\hline & $(0.129)$ & $(0.135)$ & $(0.0922)$ & $(0.214)$ & $(0.183)$ & $(0.104)$ \\
\hline \multirow[t]{2}{*}{$\ln \left(Q_{1995}\right)$} & $-0.0640 * * *$ & $-0.0533^{* * *}$ & -0.0107 & $-0.126^{* * *}$ & $-0.0958^{* * *}$ & $-0.0303^{* *}$ \\
\hline & $(0.0199)$ & $(0.0165)$ & $(0.0129)$ & $(0.0294)$ & $(0.0217)$ & $(0.0125)$ \\
\hline \multirow[t]{2}{*}{ Constant } & $0.900^{* * *}$ & $0.815^{* * *}$ & 0.0855 & $1.551^{* * *}$ & $1.252^{* * *}$ & $0.299^{* *}$ \\
\hline & $(0.208)$ & $(0.178)$ & $(0.132)$ & $(0.315)$ & $(0.223)$ & $(0.141)$ \\
\hline Observations & 348 & 348 & 348 & 348 & 348 & 348 \\
\hline R-squared & 0.139 & 0.115 & 0.053 & 0.242 & 0.224 & 0.090 \\
\hline Country FE & No & No & No & No & No & No \\
\hline
\end{tabular}

Table 3: OLS regressions. Relative wage bill share, hours worked, and wages: 1995-

2007 changes. Dependent variables are the 1995-2007 log changes in relative wage bill share, relative hours worked, and relative wages. Coefficients are estimated by ordinary least squares. All regression results are weighted by each industry-country 1995 relative employment. The weights are obtained dividing the number of employees in each industry-country in 1995 by the total employment in 1995. Robust standard errors in parenthesis. ${ }^{* * *} p<0.01,{ }^{* *} p<0.05, *$ $p<0.1$. 


\begin{tabular}{|c|c|c|c|c|c|c|}
\hline & (1) & $(2)$ & $(3)$ & (4) & $(5)$ & (6) \\
\hline VARIABLES & $\Delta \ln \left(\frac{B S^{H}}{B S^{M}}\right)$ & $\Delta \ln \left(\frac{N^{H}}{N^{M}}\right)$ & $\Delta \ln \left(\frac{W^{H}}{W^{M}}\right)$ & $\Delta \ln \left(\frac{B S^{M}}{B S^{L}}\right)$ & $\Delta \ln \left(\frac{N^{M}}{N^{L}}\right)$ & $\Delta \ln \left(\frac{W^{M}}{W^{L}}\right)$ \\
\hline \multirow[t]{2}{*}{$\Delta K / Q$} & $2.084^{* * *}$ & $2.271^{* * *}$ & -0.187 & $-1.225^{*}$ & $-0.989^{*}$ & -0.237 \\
\hline & $(0.713)$ & $(0.628)$ & $(0.252)$ & $(0.632)$ & $(0.529)$ & $(0.331)$ \\
\hline \multirow[t]{2}{*}{$\Delta C / Q$} & 0.346 & $0.365^{*}$ & -0.0199 & $0.522^{* *}$ & 0.281 & $0.242^{*}$ \\
\hline & $(0.215)$ & $(0.202)$ & $(0.0976)$ & $(0.216)$ & $(0.176)$ & $(0.145)$ \\
\hline \multirow[t]{2}{*}{$\Delta \ln (Q)$} & $-0.231^{* * *}$ & $-0.253^{* * *}$ & 0.0220 & -0.0982 & -0.0930 & -0.00522 \\
\hline & $(0.0800)$ & $(0.0734)$ & $(0.0380)$ & $(0.0715)$ & $(0.0617)$ & $(0.0490)$ \\
\hline \multirow[t]{2}{*}{$(K / Q)_{1995}$} & $2.165^{* * *}$ & $2.007 * * *$ & 0.158 & -0.149 & -0.163 & 0.0145 \\
\hline & $(0.606)$ & $(0.534)$ & $(0.192)$ & $(0.510)$ & $(0.398)$ & $(0.285)$ \\
\hline \multirow[t]{2}{*}{$(C / Q)_{1995}$} & 0.0192 & 0.120 & -0.100 & 0.136 & 0.0193 & 0.117 \\
\hline & $(0.115)$ & $(0.104)$ & $(0.0619)$ & $(0.115)$ & $(0.117)$ & $(0.0857)$ \\
\hline \multirow[t]{2}{*}{$\ln \left(Q_{1995}\right)$} & $-0.0664 * * *$ & $-0.0486^{* *}$ & -0.0178 & $-0.0391^{*}$ & -0.0207 & -0.0184 \\
\hline & $(0.0220)$ & $(0.0188)$ & $(0.0115)$ & $(0.0214)$ & $(0.0184)$ & $(0.0124)$ \\
\hline \multirow[t]{2}{*}{ Constant } & $1.088^{* * *}$ & $0.920 * * *$ & 0.168 & $0.552^{* * *}$ & $0.357^{* *}$ & 0.195 \\
\hline & $(0.218)$ & $(0.187)$ & $(0.103)$ & $(0.185)$ & $(0.158)$ & $(0.119)$ \\
\hline Observations & 348 & 348 & 348 & 348 & 348 & 348 \\
\hline R-squared & 0.388 & 0.379 & 0.623 & 0.753 & 0.716 & 0.475 \\
\hline Country FE & Yes & Yes & Yes & Yes & Yes & Yes \\
\hline
\end{tabular}

Table 4: OLS regressions. Relative wage bill share, hours worked, and wages: 19952007 changes, including country fixed effects. Dependent variables are the 1995-2007 log changes in relative wage bill share, relative hours worked, and relative wages. Coefficients are estimated by ordinary least squares, controlling for country fixed effects. All regression results are weighted by each industry-country 1995 relative employment. The weights are obtained dividing the number of employees in each industry-country in 1995 by the total employment in 1995. Robust standard errors in parenthesis. ${ }^{* * *} p<0.01,{ }^{* *} p<0.05,{ }^{*} p<0.1$. 


\begin{tabular}{|c|c|c|c|c|c|c|}
\hline & (1) & $(2)$ & $(3)$ & (4) & $(5)$ & (6) \\
\hline VARIABLES & $\Delta \ln \left(\frac{B S^{H}}{B S^{M}}\right)$ & $\Delta \ln \left(\frac{N^{H}}{N^{M}}\right)$ & $\Delta \ln \left(\frac{W^{H}}{W^{M}}\right)$ & $\Delta \ln \left(\frac{B S^{M}}{B S^{L}}\right)$ & $\Delta \ln \left(\frac{N^{M}}{N^{L}}\right)$ & $\Delta \ln \left(\frac{W^{M}}{W^{L}}\right)$ \\
\hline \multirow[t]{2}{*}{$\Delta K / Q$} & $1.867^{* * *}$ & $1.466^{* *}$ & 0.401 & $-2.554^{* *}$ & $-1.891^{* *}$ & -0.663 \\
\hline & $(0.686)$ & $(0.643)$ & $(0.404)$ & (1.117) & $(0.890)$ & $(0.436)$ \\
\hline \multirow[t]{2}{*}{$\Delta C / Q$} & 0.327 & 0.245 & 0.0820 & -0.143 & -0.123 & -0.0198 \\
\hline & $(0.357)$ & $(0.377)$ & $(0.309)$ & $(0.759)$ & $(0.633)$ & $(0.261)$ \\
\hline \multirow[t]{2}{*}{$\Delta \ln (Q)$} & $-0.191^{*}$ & -0.119 & -0.0718 & $0.515^{* * *}$ & $0.518^{* * *}$ & -0.00218 \\
\hline & $(0.113)$ & $(0.103)$ & $(0.0601)$ & $(0.164)$ & $(0.147)$ & $(0.0738)$ \\
\hline \multirow[t]{2}{*}{$(K / Q)_{1995}$} & $2.047^{* * *}$ & $1.646^{* * *}$ & 0.401 & -0.320 & -0.120 & -0.200 \\
\hline & $(0.612)$ & $(0.569)$ & $(0.301)$ & $(0.889)$ & $(0.658)$ & $(0.372)$ \\
\hline \multirow[t]{2}{*}{$(C / Q)_{1995}$} & -0.0104 & 0.0896 & -0.100 & -0.0837 & -0.221 & 0.137 \\
\hline & $(0.128)$ & $(0.153)$ & $(0.103)$ & $(0.258)$ & $(0.218)$ & $(0.129)$ \\
\hline \multirow[t]{2}{*}{$\ln \left(Q_{1995}\right)$} & $-0.0651^{*}$ & -0.0370 & -0.0281 & $-0.100^{* *}$ & $-0.0578^{*}$ & $-0.0425^{* *}$ \\
\hline & $(0.0332)$ & $(0.0282)$ & $(0.0191)$ & $(0.0429)$ & $(0.0327)$ & $(0.0196)$ \\
\hline \multirow[t]{2}{*}{ Constant } & $0.915^{* *}$ & $0.645^{* *}$ & 0.270 & $1.200 * *$ & $0.770 * *$ & $0.429 *$ \\
\hline & $(0.372)$ & $(0.324)$ & $(0.213)$ & $(0.489)$ & $(0.358)$ & $(0.237)$ \\
\hline Observations & 156 & 156 & 156 & 156 & 156 & 156 \\
\hline R-squared & 0.136 & 0.096 & 0.044 & 0.235 & 0.224 & 0.094 \\
\hline Country FE & No & No & No & Yes & No & No \\
\hline
\end{tabular}

Table 5: OLS regressions. Relative wage bill share, hours worked, and wages: 1995-

2007 changes. Service Industries only. Dependent variables are the 1995-2007 log changes in relative wage bill share, relative hours worked, and relative wages. Coefficients are estimated by ordinary least squares controlling for year, country, and code fixed effects. All regression results are weighted by each industry-country 1995 relative employment. The weights are obtained dividing the number of employees in each industry-country in 1995 by the total employment in 1995. Robust standard errors in parenthesis. ${ }^{* * *} p<0.01,{ }^{* *} p<0.05,{ }^{*} p<0.1$. 


\begin{tabular}{|c|c|c|c|c|c|c|}
\hline & (1) & $(2)$ & (3) & (4) & (5) & (6) \\
\hline VARIABLES & $\Delta \ln \left(\frac{B S^{H}}{B S^{M}}\right)$ & $\Delta \ln \left(\frac{N^{H}}{N^{M}}\right)$ & $\Delta \ln \left(\frac{W^{H}}{W^{M}}\right)$ & $\Delta \ln \left(\frac{B S^{M}}{B S^{L}}\right)$ & $\Delta \ln \left(\frac{N^{M}}{N^{L}}\right)$ & $\Delta \ln \left(\frac{W^{M}}{W^{L}}\right)$ \\
\hline \multirow[t]{2}{*}{$\Delta K / Q$} & 4.076 & $3.561^{*}$ & 0.514 & -1.241 & -0.812 & -0.429 \\
\hline & $(2.800)$ & $(2.133)$ & $(0.916)$ & $(1.333)$ & $(1.031)$ & $(0.877)$ \\
\hline \multirow[t]{2}{*}{$\Delta C / Q$} & 0.347 & -0.0387 & $0.385^{* * *}$ & $-0.585^{* * *}$ & $-0.750^{* * *}$ & $0.165^{*}$ \\
\hline & $(0.353)$ & $(0.301)$ & $(0.142)$ & $(0.193)$ & $(0.189)$ & $(0.0881)$ \\
\hline \multirow[t]{2}{*}{$\Delta \ln (Q)$} & $-0.348^{* *}$ & $-0.244^{* *}$ & -0.104 & $0.324^{* * *}$ & $0.297^{* * *}$ & 0.0270 \\
\hline & $(0.138)$ & $(0.118)$ & $(0.0635)$ & $(0.0937)$ & $(0.0731)$ & $(0.0659)$ \\
\hline \multirow[t]{2}{*}{$(K / Q)_{1995}$} & $3.118^{*}$ & 2.098 & 1.020 & -0.800 & -0.729 & -0.0712 \\
\hline & $(1.765)$ & $(1.344)$ & $(0.861)$ & $(1.114)$ & $(0.796)$ & $(0.651)$ \\
\hline \multirow[t]{2}{*}{$(C / Q)_{1995}$} & -0.151 & 0.118 & $-0.269^{*}$ & $0.535^{* *}$ & $0.417^{* *}$ & 0.117 \\
\hline & $(0.280)$ & $(0.243)$ & $(0.156)$ & $(0.226)$ & $(0.204)$ & $(0.0977)$ \\
\hline \multirow[t]{2}{*}{$\ln \left(Q_{1995}\right)$} & $-0.101^{* *}$ & $-0.0968^{* * *}$ & -0.00373 & $-0.0770^{* * *}$ & $-0.0666^{* * *}$ & -0.0103 \\
\hline & $(0.0443)$ & $(0.0366)$ & $(0.0214)$ & $(0.0285)$ & $(0.0151)$ & $(0.0212)$ \\
\hline \multirow[t]{2}{*}{ Constant } & $1.241^{* * *}$ & $1.214^{* * *}$ & 0.0264 & $1.035^{* * *}$ & $0.933^{* * *}$ & 0.101 \\
\hline & $(0.429)$ & $(0.360)$ & $(0.200)$ & $(0.258)$ & $(0.172)$ & $(0.178)$ \\
\hline Observations & 192 & 192 & 192 & 192 & 192 & 192 \\
\hline R-squared & 0.197 & 0.208 & 0.120 & 0.355 & 0.395 & 0.053 \\
\hline Country FE & No & No & No & No & No & No \\
\hline
\end{tabular}

Table 6: OLS regressions. Relative wage bill share, hours worked, and wages: 19952007 changes. Manufacturing Industries only. Dependent variables are the 1995-2007 log changes in relative wage bill share, relative hours worked, and relative wages. Coefficients are estimated by ordinary least squares controlling for year, country, and code fixed effects. All regression results are weighted by each industry-country 1995 relative employment. The weights are obtained dividing the number of employees in each industry-country in 1995 by the total employment in 1995. Robust standard errors in parenthesis. ${ }^{* * *} p<0.01,{ }^{* *} p<0.05,{ }^{*}$ $p<0.1$. 


\begin{tabular}{|c|c|c|c|c|c|c|}
\hline & (1) & $(2)$ & (3) & (4) & $(5)$ & (6) \\
\hline VARIABLES & $\Delta \ln \left(\frac{B S^{H}}{B S^{M}}\right)$ & $\Delta \ln \left(\frac{N^{H}}{N^{M}}\right)$ & $\Delta \ln \left(\frac{W^{H}}{W^{M}}\right)$ & $\Delta \ln \left(\frac{B S^{M}}{B S^{L}}\right)$ & $\Delta \ln \left(\frac{N^{M}}{N^{L}}\right)$ & $\Delta \ln \left(\frac{W^{M}}{W^{L}}\right)$ \\
\hline \multirow[t]{2}{*}{$\Delta K / Q$} & $3.927^{* *}$ & $3.496^{* * *}$ & 0.253 & $-1.769^{*}$ & $-1.491^{*}$ & -0.283 \\
\hline & $(1.730)$ & $(1.308)$ & $(0.608)$ & $(1.025)$ & $(0.876)$ & $(0.463)$ \\
\hline \multirow[t]{2}{*}{$\Delta C / Q$} & $0.398^{*}$ & $0.404^{* *}$ & -0.0101 & $0.506^{* *}$ & 0.270 & $0.254^{*}$ \\
\hline & $(0.219)$ & $(0.201)$ & $(0.0957)$ & $(0.208)$ & $(0.165)$ & $(0.140)$ \\
\hline \multirow[t]{2}{*}{$\Delta \ln (Q)$} & $-0.267^{* * *}$ & $-0.274^{* * *}$ & 0.00662 & -0.0836 & -0.0801 & -0.00827 \\
\hline & $(0.0933)$ & $(0.0811)$ & $(0.0381)$ & $(0.0726)$ & $(0.0615)$ & $(0.0490)$ \\
\hline \multirow[t]{2}{*}{$(K / Q)_{1995}$} & $2.978^{* * *}$ & $2.539 * * *$ & 0.330 & -0.365 & -0.362 & -0.0265 \\
\hline & $(0.966)$ & $(0.773)$ & $(0.303)$ & $(0.623)$ & $(0.507)$ & $(0.299)$ \\
\hline \multirow[t]{2}{*}{$(C / Q)_{1995}$} & 0.0341 & 0.127 & -0.100 & 0.128 & 0.0147 & 0.122 \\
\hline & $(0.112)$ & $(0.0981)$ & $(0.0617)$ & $(0.110)$ & $(0.113)$ & $(0.0822)$ \\
\hline \multirow[t]{2}{*}{$\ln \left(Q_{1995}\right)$} & $-0.0498^{* *}$ & $-0.0380^{* *}$ & -0.0135 & $-0.0435^{* *}$ & -0.0248 & -0.0185 \\
\hline & $(0.0211)$ & $(0.0185)$ & $(0.0116)$ & $(0.0215)$ & $(0.0189)$ & $(0.0118)$ \\
\hline \multirow[t]{2}{*}{ Constant } & $0.923^{* * *}$ & $0.815^{* * *}$ & 0.129 & $0.596^{* * *}$ & $0.397^{* *}$ & $0.197^{*}$ \\
\hline & $(0.207)$ & $(0.180)$ & $(0.107)$ & $(0.186)$ & $(0.162)$ & $(0.111)$ \\
\hline Observations & 348 & 348 & 348 & 348 & 348 & 348 \\
\hline R-squared & 0.364 & 0.366 & 0.619 & 0.751 & 0.715 & 0.474 \\
\hline Country FE & Yes & Yes & Yes & Yes & Yes & Yes \\
\hline First stage F-stat & 8.828 & 8.828 & 8.828 & 8.828 & 8.828 & 8.828 \\
\hline Prob $>$ chi 2 & 0.0121 & 0.0121 & 0.0121 & 0.0121 & 0.0121 & 0.0121 \\
\hline CLR test statistic & 6.790 & 9.389 & 0.169 & 3.649 & 3.599 & 0.408 \\
\hline CLR test pvalue & 0.0104 & 0.00267 & 0.685 & 0.0612 & 0.0628 & 0.531 \\
\hline
\end{tabular}

Table 7: IV regressions. Relative wage bill share, hours worked, and wages: 1995-

2007 changes. Dependent variables are the 1995-2007 log changes in relative wage bill share, relative hours worked, and relative wages. Coefficients are estimated by ordinary least squares controlling country fixed effects. All regression results are weighted by each industry-country 1995 relative employment. The weights are obtained dividing the number of employees in each industry-country in 1995 by the total employment figure in 1995. Robust standard errors in parenthesis. ${ }^{* * *} p<0.01,{ }^{* *} p<0.05,{ }^{*} p<0.1$. 


\begin{tabular}{|c|c|c|c|c|c|c|}
\hline & (1) & $(2)$ & $(3)$ & $(4)$ & $(5)$ & (6) \\
\hline VARIABLES & $\Delta \ln \left(\frac{B S^{H}}{B S^{M}}\right)$ & $\Delta \ln \left(\frac{N^{H}}{N^{M}}\right)$ & $\Delta \ln \left(\frac{W^{H}}{W^{M}}\right)$ & $\Delta \ln \left(\frac{B S^{M}}{B S^{L}}\right)$ & $\Delta \ln \left(\frac{N^{M}}{N^{L}}\right)$ & $\Delta \ln \left(\frac{W^{M}}{W^{L}}\right)$ \\
\hline \multirow[t]{2}{*}{$\Delta K / Q$} & $3.038^{* *}$ & $2.677^{* *}$ & 0.364 & $-2.841^{*}$ & $-2.367^{*}$ & -0.421 \\
\hline & $(1.511)$ & (1.237) & $(0.582)$ & $(1.482)$ & $(1.222)$ & $(0.609)$ \\
\hline \multirow[t]{2}{*}{$\Delta C / Q$} & 0.290 & 0.204 & 0.0837 & -0.0949 & -0.0245 & 0.00329 \\
\hline & $(0.353)$ & $(0.377)$ & $(0.305)$ & $(0.734)$ & $(0.602)$ & $(0.249)$ \\
\hline \multirow[t]{2}{*}{$\Delta \ln (Q)$} & $-0.189^{*}$ & -0.118 & -0.0718 & $0.510^{* * *}$ & $0.512^{* * *}$ & -0.00519 \\
\hline & $(0.112)$ & $(0.103)$ & $(0.0587)$ & $(0.159)$ & $(0.141)$ & $(0.0719)$ \\
\hline \multirow[t]{2}{*}{$(K / Q)_{1995}$} & $2.545^{* * *}$ & $2.159^{* * *}$ & 0.385 & -0.411 & -0.297 & -0.126 \\
\hline & $(0.884)$ & $(0.754)$ & $(0.311)$ & $(0.896)$ & $(0.723)$ & $(0.336)$ \\
\hline \multirow{2}{*}{$(C / Q)_{1995}$} & -0.0158 & 0.0823 & -0.100 & -0.0686 & -0.204 & 0.126 \\
\hline & $(0.125)$ & $(0.146)$ & $(0.0981)$ & $(0.248)$ & $(0.209)$ & $(0.125)$ \\
\hline \multirow[t]{2}{*}{$\ln \left(Q_{1995}\right)$} & $-0.0599 *$ & -0.0326 & -0.0281 & $-0.0997^{* *}$ & $-0.0599^{*}$ & $-0.0449^{* *}$ \\
\hline & $(0.0307)$ & $(0.0281)$ & $(0.0180)$ & $(0.0408)$ & $(0.0315)$ & $(0.0180)$ \\
\hline \multirow[t]{2}{*}{ Constant } & $0.834^{* *}$ & $0.572^{*}$ & 0.271 & $1.199 * * *$ & $0.800^{* *}$ & $0.451^{* *}$ \\
\hline & $(0.349)$ & $(0.326)$ & $(0.201)$ & $(0.461)$ & $(0.342)$ & $(0.219)$ \\
\hline Observations & 156 & 156 & 156 & 156 & 156 & 156 \\
\hline R-squared & 0.121 & 0.076 & 0.044 & 0.235 & 0.223 & 0.090 \\
\hline First stage F-stat & 7.922 & 7.922 & 7.922 & 7.922 & 7.922 & 7.922 \\
\hline Prob $>$ chi2 & 0.0190 & 0.0190 & 0.0190 & 0.0190 & 0.0190 & 0.0190 \\
\hline CLR test statistic & 5.985 & 7.221 & 0.415 & 3.571 & 4.153 & 0.488 \\
\hline CLR test pvalue & 0.0163 & 0.00826 & 0.529 & 0.0656 & 0.0469 & 0.494 \\
\hline
\end{tabular}

Table 8: IV regressions. Relative wage bill share, hours worked, and wages: 19952007 changes. Service Industries only. Dependent variables are the 1995-2007 log changes in relative wage bill share, relative hours worked, and relative wages. Coefficients are estimated by ordinary least squares controlling for country fixed effects. All regression results are weighted by each industry-country 1995 relative employment. The weights are obtained dividing the number of employees in each industry-country in 1995 by the total employment figure in 1995 . Robust standard errors in parenthesis. ${ }^{* * *} p<0.01,{ }^{* *} p<0.05,{ }^{*} p<0.1$. 


\begin{tabular}{|c|c|c|c|c|c|c|}
\hline & (1) & $(2)$ & $(3)$ & $(4)$ & $(5)$ & $(6)$ \\
\hline VARIABLES & $\Delta \ln \left(\frac{B S^{H}}{B S^{M}}\right)$ & $\Delta \ln \left(\frac{N^{H}}{N^{M}}\right)$ & $\Delta \ln \left(\frac{W^{H}}{W^{M}}\right)$ & $\Delta \ln \left(\frac{B S^{M}}{B S^{L}}\right)$ & $\Delta \ln \left(\frac{N^{M}}{N^{L}}\right)$ & $\Delta \ln \left(\frac{W^{M}}{W^{L}}\right)$ \\
\hline \multirow[t]{2}{*}{$\Delta K / Q$} & 15.78 & 11.33 & 4.584 & -1.334 & -3.000 & 2.345 \\
\hline & $(10.04)$ & $(7.871)$ & (4.938) & $(5.163)$ & $(3.583)$ & $(3.226)$ \\
\hline \multirow[t]{2}{*}{$\Delta C / Q$} & 0.266 & -0.0703 & $0.396^{* *}$ & $-0.587^{* * *}$ & $-0.764^{* * *}$ & $0.209^{* *}$ \\
\hline & $(0.472)$ & $(0.359)$ & $(0.184)$ & $(0.192)$ & $(0.193)$ & $(0.0916)$ \\
\hline \multirow[t]{2}{*}{$\Delta \ln (Q)$} & $-0.374^{* *}$ & $-0.258^{* *}$ & $-0.125^{*}$ & $0.324^{* * *}$ & $0.305^{* * *}$ & -0.00590 \\
\hline & $(0.150)$ & $(0.117)$ & $(0.0677)$ & $(0.0899)$ & $(0.0719)$ & $(0.0607)$ \\
\hline \multirow[t]{2}{*}{$(K / Q)_{1995}$} & $7.053^{*}$ & 4.624 & 2.189 & -0.835 & -1.388 & 0.862 \\
\hline & $(4.278)$ & $(3.180)$ & $(2.100)$ & $(2.196)$ & $(1.510)$ & $(1.319)$ \\
\hline \multirow[t]{2}{*}{$(C / V A)_{1995}$} & 0.0210 & 0.242 & -0.182 & $0.533^{* *}$ & $0.374^{*}$ & 0.189 \\
\hline & $(0.305)$ & $(0.255)$ & $(0.159)$ & $(0.237)$ & $(0.208)$ & $(0.119)$ \\
\hline \multirow[t]{2}{*}{$\ln \left(Q_{1995}\right)$} & $-0.0875^{* *}$ & $-0.0865^{* * *}$ & -0.00221 & $-0.0770 * * *$ & $-0.0685^{* * *}$ & -0.0135 \\
\hline & $(0.0403)$ & $(0.0297)$ & $(0.0219)$ & $(0.0267)$ & $(0.0153)$ & $(0.0178)$ \\
\hline \multirow[t]{2}{*}{ Constant } & $0.937^{* * *}$ & $0.995^{* * *}$ & -0.0519 & $1.037^{* * *}$ & $0.985^{* * *}$ & 0.0813 \\
\hline & $(0.339)$ & $(0.270)$ & $(0.197)$ & $(0.236)$ & $(0.184)$ & $(0.131)$ \\
\hline Observations & 192 & 192 & 192 & 192 & 192 & 192 \\
\hline R-squared & 0.008 & 0.094 & 0.027 & 0.355 & 0.383 & -0.076 \\
\hline First stage F-stat & 4.615 & 4.615 & 4.615 & 4.615 & 4.615 & 4.615 \\
\hline Prob $>$ chi2 & 0.0995 & 0.0995 & 0.0995 & 0.0995 & 0.0995 & 0.0995 \\
\hline CLR test statistic & 3.084 & 2.150 & 1.100 & 0.0664 & 0.749 & 1.281 \\
\hline CLR test pvalue & 0.0986 & 0.172 & 0.320 & 0.809 & 0.418 & 0.290 \\
\hline
\end{tabular}

Table 9: IV regressions. Relative wage bill share, hours worked, and wages: 19952007 changes. Manufacturing Industries only. Dependent variables are the 1995-2007 log changes in relative wage bill share, relative hours worked, and relative wages. Coefficients are estimated by ordinary least squares controlling for country fixed effects. All regression results are weighted by each industry-country 1995 relative employment. The weights are obtained dividing the number of employees in each industry-country in 1995 by the total employment figure in 1995. Robust standard errors in parenthesis. ${ }^{* * *} p<0.01,{ }^{* *} p<0.05,{ }^{*} p<0.1$. 
Table 10: Descriptive statistics about wage and inequality dynamics

\begin{tabular}{cccccccc}
\hline \multicolumn{7}{c}{ Panel A: log Gross Current wages } \\
\hline mean & p10 & p50 & p90 & $\mathbf{9 0 - 1 0}$ & $\mathbf{9 0 - 5 0}$ & $\mathbf{5 0 - 1 0}$ \\
\hline 1996 & 2.147 & 1.542 & 2.143 & 2.780 & 1.238 & 0.637 & 0.601 \\
2007 & 2.292 & 1.562 & 2.276 & 3.046 & 1.484 & 0.770 & 0.714 \\
\hline Time change & 0.146 & 0.020 & 0.133 & 0.266 & 0.246 & 0.133 & 0.113 \\
\hline
\end{tabular}

\begin{tabular}{|c|c|c|c|c|c|c|c|}
\hline \multicolumn{8}{|c|}{ Panel B: log Gross Current wages in PPP } \\
\hline & mean & p10 & p50 & p90 & $90-10$ & $90-50$ & $50-10$ \\
\hline 1996 & 2.285 & 1.722 & 2.263 & 2.914 & 1.192 & 0.651 & 0.541 \\
\hline 2007 & 2.327 & 1.690 & 2.299 & 3.017 & 1.327 & 0.718 & 0.609 \\
\hline Time change & 0.042 & -0.032 & 0.036 & 0.103 & 0.135 & 0.068 & 0.067 \\
\hline \multicolumn{8}{|c|}{ Panel C: log Gross Yearly Earnings } \\
\hline & mean & p10 & p50 & p90 & $90-10$ & $90-50$ & $50-10$ \\
\hline 1996 & 9.967 & 9.343 & 9.934 & 10.628 & 1.285 & 0.694 & 0.591 \\
\hline 2007 & 10.051 & 9.306 & 10.050 & 10.759 & 1.453 & 0.709 & 0.744 \\
\hline Time change & 0.084 & -0.037 & 0.116 & 0.131 & 0.168 & 0.014 & 0.154 \\
\hline
\end{tabular}

\begin{tabular}{ccccccccc}
\hline \multicolumn{10}{c}{ Panel D: log Gross } & Yearly Earnings in PPP & \\
\hline & mean & p10 & p50 & p90 & $\mathbf{9 0 - 1 0}$ & $\mathbf{9 0 - 5 0}$ & $\mathbf{5 0 - 1 0}$ \\
\hline 1996 & 10.030 & 9.412 & 10.012 & 10.646 & 1.234 & 0.634 & 0.600 \\
2007 & 10.046 & 9.358 & 10.039 & 10.715 & 1.357 & 0.677 & 0.680 \\
\hline Time change & 0.016 & -0.054 & 0.026 & 0.070 & 0.123 & 0.043 & 0.080 \\
\hline
\end{tabular}

*Observations: 89,453 for the Gross Current Wage sample, 119,103 for the Gross Yearly Earnings sample. 
Table 11: Dynamics of labour market composition in Europe

\begin{tabular}{rccccccr}
\hline \multicolumn{7}{c}{ Panel A: smaple of log Gross Current wages } \\
\hline year & female & exp pot & primary & secondary & tertiary & temporary & part time \\
\hline 1996 & 0.37 & 18.36 & 0.40 & 0.37 & 0.23 & 0.10 & 0.05 \\
2007 & 0.42 & 18.91 & 0.28 & 0.45 & 0.27 & 0.13 & 0.09 \\
\hline & manufac & wholesale & rest/transport & fin/business serv. & public & educ/health & other services \\
\hline 1996 & 0.35 & 0.12 & 0.11 & 0.11 & 0.09 & 0.17 & 0.05 \\
2007 & 0.31 & 0.13 & 0.11 & 0.13 & 0.09 & 0.17 & 0.06 \\
\hline \multicolumn{7}{c}{ Panel B: sample of log Gross Yearly Earnings } \\
\hline year & female & exp pot & primary & secondary & tertiary & temporary & part time \\
\hline 1996 & 0.41 & 19.64 & 0.35 & 0.39 & 0.26 & 0.05 & 0.07 \\
2007 & 0.46 & 19.41 & 0.24 & 0.47 & 0.30 & 0.09 & 0.14 \\
\hline & manufac & wholesale & rest/transport & fin/business serv. & public & educ/health & other services \\
\hline 1996 & 0.32 & 0.12 & 0.09 & 0.11 & 0.10 & 0.21 & 0.05 \\
2007 & 0.28 & 0.13 & 0.09 & 0.12 & 0.11 & 0.20 & 0.06 \\
\hline
\end{tabular}

*Observations: 89,453 for the Gross Current Wage sample, 119,103 for the Gross Yearly Earnings sample. 
Table 12: Gross current hourly wages: Composition and wage structure effect

\begin{tabular}{|c|c|c|c|c|c|c|}
\hline & \multicolumn{2}{|c|}{$90-10$} & \multicolumn{2}{|c|}{$90-50$} & \multicolumn{2}{|c|}{$50-10$} \\
\hline & Coeff & t-stat & Coeff & t-stat & Coeff & t-stat \\
\hline Change in the index & 0.245 & 14.27 & 0.133 & 10.12 & 0.112 & 8.97 \\
\hline Total composition & 0.019 & 2.74 & 0.019 & 4.08 & 0.000 & 0.08 \\
\hline Total wage structure & 0.230 & 17.41 & 0.125 & 11.44 & 0.105 & 9.56 \\
\hline \multicolumn{7}{|c|}{ Detailed composition effect } \\
\hline Demographic & 0.006 & 2.60 & 0.001 & 0.57 & 0.005 & 2.59 \\
\hline Education & -0.024 & -4.34 & -0.004 & -1.04 & -0.020 & -4.51 \\
\hline Institution & 0.015 & 4.64 & 0.012 & 6.20 & 0.003 & 1.30 \\
\hline Industry & 0.005 & 1.95 & 0.004 & 1.70 & 0.001 & 1.13 \\
\hline Offshorability & 0.012 & 5.12 & 0.005 & 4.11 & 0.006 & 3.54 \\
\hline \multicolumn{7}{|l|}{ Technology } \\
\hline - Abstract & 0.002 & 1.44 & 0.001 & 1.08 & 0.001 & 1.30 \\
\hline - Routine & 0.000 & 0.27 & 0.000 & 0.66 & 0.000 & -0.21 \\
\hline - Service & 0.003 & 0.82 & 0.000 & -0.23 & 0.003 & 1.19 \\
\hline \multicolumn{7}{|c|}{ Detailed wage structure effect } \\
\hline Demographic & 0.030 & 0.74 & -0.068 & -1.95 & 0.098 & 3.44 \\
\hline Education & 0.013 & 0.69 & 0.020 & 1.55 & -0.007 & -0.46 \\
\hline Institution & 0.013 & 1.49 & 0.000 & 0.08 & 0.013 & 1.47 \\
\hline Industry & -0.006 & -0.22 & -0.001 & -0.06 & -0.005 & -0.25 \\
\hline Offshorability & -0.019 & -2.05 & -0.011 & -1.73 & -0.008 & -0.99 \\
\hline \multicolumn{7}{|l|}{ Technology } \\
\hline - Abstract & 0.056 & 4.07 & 0.043 & 3.81 & 0.013 & 1.38 \\
\hline - Routine & -0.028 & -1.95 & -0.011 & -1.11 & -0.017 & -1.17 \\
\hline - Service & -0.052 & -2.74 & -0.015 & -1.22 & -0.036 & -2.09 \\
\hline Reweighing error & 0.004 & 0.93 & 0.004 & 1.57 & 0.000 & -0.11 \\
\hline Specification error & -0.008 & -0.46 & -0.016 & -1.18 & 0.008 & 0.56 \\
\hline
\end{tabular}

*Standard errors are computed bootstrapping the whole procedure (100 replications). 


\section{A Annex: Micro data}

To study the dynamic of labor earnings in Europe in recent years, we use wave 1996 of ECHP and wave 2007-4 of EU-Silc, as explained in subsection 3.

Both surveys collect information on current gross monthly earnings on main job, relative to the month in which respondent is interviewed, and on the annual earnings referred to the calendar year previous the interview.

Current gross monthly earnings are defined as the monthly amounts earned by employees in the main job, including usual paid overtime, both in ECHP (variable PI211MG) and in EU-Silc (PY200G). From gross monthly earnings we derive hourly wage by multiplying them by $12 / 52$, and dividing by the the number of hours usually worked per week in the current main job (PE005A for ECHP, PL060 for EU-Silc). However, this variable is available in both surveys only for AT, ES, GR, IE, IT, PT and UK.

Then we consider annual earnings (variable PI111 for ECHP, PY010G for EU-Silc), which allow to consider all EU15 countries, with the exception of Netherland and Sweden. ${ }^{24}$ Annual earnings include monthly wages, 13th and 14th salary, extra payments for overtime, holiday pay, earnings from an additional job, other earnings not specified separately, and lump sums payments. EU-Silc provides annual earnings gross of income taxes and social security contribution, while in ECHP amounts are net, with the exception of FI and FR. To compare earnings over time, we need to convert ECHP net amounts to gross, using the net/gross factor (HI020), which has the shortcoming of being constant for all income components.

On the contrary, current monthly earnings are always gross, both in ECHP and EU-Silc, even if it is available for a smaller set of countries. Based on these considerations, we decide to use both definitions of earnings in our analysis, in order to enforce our findings and/or to enlighten possible discrepancies when using different definitions of earnings.

We also consider a set of covariates of interest, to better interpret changes in earnings inequality in Europe during the period observed. The covariates selected are: gender, education level, type of contract (permanent or fixed-term), whether employee is working full or part-

\footnotetext{
${ }^{24}$ Actually, data on annual earnings for NL are available both in ECHP and EU-Silc, but some of the covariates of interest are missing, so that we exclude NL from our sample.
} 
time, industry and potential labor experience. The definitions of these covariates are largely comparable between the two surveys.

In few cases, namely industry and potential labor experience, there are some differences. As for industry sector, in both sources industry classifications, based on NACE-REV 1.1, are more detailed than the one we use. However, they are not fully comparable. For instance, in ECHP (variable PE007B) information about section section D, Manufacturing, is available on its own, while in EU-Silc (variable PL110) section D is grouped with section C and E, Mining and Electricity. Hence we have grouped some sectors in order to match the two classifications. Eventually we obtain the following classification with seven macro-sector: Manufacturing, Wholesale, Restoration and Transport, Financial Intermediation and Business Activities, Public Administration, Education and Health, Others Services.

Another relevant covariate is the potential labor experience, considering the age at which one attained the highest level of education. ECHP provides the age when the highest level of education was completed (PT023). If this variable is missing, but the highest level of education attained was less than secondary education (ISCED 0-2, variable PT022), we assume that respondent potentially could began to work at the age of 14. As for EU-Silc, potential labor experience is based on the year when highest level of education was attained (PE030). The flag variable of PE030 identify those that have never been in education. For these respondents we assume that they could not start to work earlier that at the age of 10 .

Education level is provided by variable PT022 for ECHP, and PE040 for EU-Silc. In both surveys, educational attainments are defined following the International Standard Classification of Education (ISCED). In ECHP the variable has three levels, "lower than upper secondary education", "upper secondary education completed", and "first stage of tertiary education completed", which correspond to ISCED levels $0-1,2$ and $3-5,$, respectively. Then we have grouped the more detailed ISCED levels provided by EU-Silc into these three categories.

As for the remaining covariates, respondent's genre is derived from variables PD004 for ECHP and PB150 for EU-Silc; the type of contract, of limited or unlimited duration, is collected from PE024 for ECHP and from PL140 for EU-Silc; variables PE005c for ECHP and PL030 for EU-Silc allows to distinguish between full-time and part-time workers. 
Finally, we consider some variables that measure the skill requirements at the occupation level, and an index of the offshorability of each occupation. The description of these variables and of the related data sources are provided in subsection 3.2. Note that there are some discrepancies between occupation classifications in Goos et al. (2014) and in ECHP and EUSilc. All classification refer to the ISCO 2-digit. However, differently from Goos et al. (2014) and from EU-Silc, in ECHP some occupations are grouped together. For instance, ISCO 11 (Legislators, senior officials and managers) and ISCO 12 (Corporate managers) are merged in a single occupation. Hence, for those cases we obtain the corresponding measures computing the weighted mean of the values of Routine, Abstract, Service and Offshorability, with weights given by the share of employees in each occupation, provided by Eurostat. 


\section{B Annex: Industry-level data}

Table B: Hours worked by high skilled, medium skilled, low skilled, using WIOD, EU KLEMS, and EUROSTAT data, 1995. Sample weights used.

\begin{tabular}{rccccccccc}
\hline & \multicolumn{3}{c}{ KLEMS } & \multicolumn{3}{c}{ WIOD } & \multicolumn{3}{c}{ EUROSTAT } \\
\hline Country & HS & MS & LS & HS & MS & LS & HS & MS & LS \\
\hline AUT & 9.7 & 65.2 & 25.1 & 12.0 & 64.6 & 23.3 & 8.8 & 64.7 & 26.5 \\
BEL & - & - & - & 13.9 & 48.8 & 37.3 & 29.9 & 37.3 & 32.8 \\
DNK & 5.9 & 60.7 & 33.3 & 23.6 & 53.5 & 22.9 & 26.1 & 53.7 & 20.2 \\
ESP & 15.9 & 22.7 & 61.4 & 21.2 & 15.6 & 63.1 & 21.7 & 16.6 & 61.8 \\
FIN & 32.0 & 41.1 & 26.9 & 30.6 & 42.5 & 26.9 & 24.2 & 48.3 & 27.4 \\
FRA & 11.1 & 61.7 & 27.2 & 21.8 & 41.7 & 36.4 & 21.5 & 45.8 & 32.7 \\
GER & 8.3 & 65.0 & 26.7 & 21.7 & 62.2 & 16.0 & 24.2 & 59.9 & 15.9 \\
IRE & - & - & - & 21.0 & 39.9 & 39.1 & 26.1 & 32.8 & 41.1 \\
ITA & 8.1 & 89.3 & 2.6 & 8.6 & 35.5 & 55.9 & 9.6 & 36.2 & 54.2 \\
NLD & 8.1 & 83.7 & 8.2 & 19.7 & 46.9 & 33.3 & 23.0 & 40.0 & 37.0 \\
SWE & - & - & - & 18.8 & 56.4 & 24.8 & 27.8 & 47.8 & 24.4 \\
UK & 12.7 & 68.5 & 18.8 & 23.0 & 42.3 & 34.7 & 23.5 & 33.8 & 42.7 \\
\hline
\end{tabular}

